Center for

Mathematical Economics

Working Papers

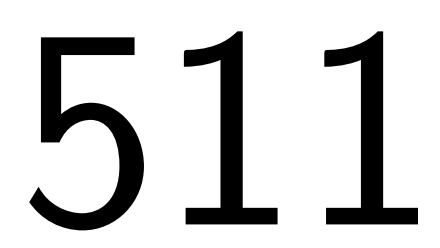

June 2014

\title{
Explaining the U-shape of the referral hiring pattern in a search model with heterogeneous workers
}

Yuliia Stupnytska and Anna Zaharieva

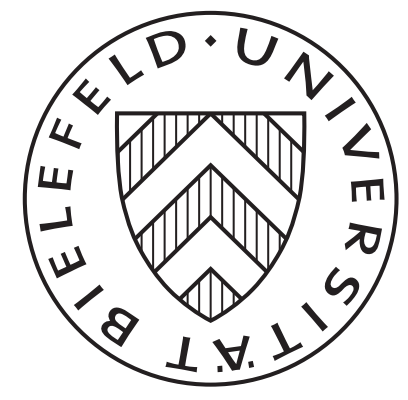




\title{
Explaining the U-shape of the referral hiring pattern in a search model with heterogeneous workers
}

\author{
Yuliia Stupnytska*, Anna Zaharieva ${ }^{\dagger}$
}

June 13, 2014

\begin{abstract}
This paper presents a search model with heterogeneous workers, social networks and endogenous search intensity. There are three job search channels available to the unemployed: costly formal applications and two costless informal channels - through family and professional networks. The gain from being employed is increasing in the productivity, so the lowest motivation for preparing formal applications is proved to be among the least productive worker types. We assume that professional contacts exhibit a strong degree of homophily, thus it is profitable for firms to direct their network search towards the more productive incumbent employees. So the probability of a professional referral is increasing in the productivity of the worker, which mitigates the incentives to use the formal channel of search. Therefore, the model predicts that workers in the right (left) tail of the productivity distribution have the highest propensity of finding a job with a help of professional (family) contacts, whereas the formal channel of search is mostly utilized by workers in the middle range of the distribution. This explains the U-shaped referral hiring pattern in the model. The endogenous sorting of workers across channels also implies that professional (family) referrals are associated with wage premiums (penalties) compared to the formal channel of search. The average effect of referrals on wages is, however, ambiguous and depends on the relative proportions of high and low productivity types in the population. These findings help to explain the contradicting empirical evidence concerning the effect of referrals on wages.
\end{abstract}

Keywords: endogenous search intensity, family contacts, professional networks, U-shape, referral puzzle, wage premiums and penalties

JEL Classification: J23, J31, J38, J64

\footnotetext{
${ }^{*}$ Corresponding author. Center for Mathematical Economics, Bielefeld University, 33501 Bielefeld, Germany. Email: ystupnytska@uni-bielefeld.de. Phone: +4917699600132

${ }^{\dagger}$ Center for Mathematical Economics, Bielefeld University, 33501 Bielefeld, Germany. Email: azaharieva@wiwi.uni-bielefeld.de
} 


\section{Introduction}

The purpose of this article is to develop a labour market matching model with heterogeneous workers, social networks and referrals. We investigate which worker groups are more likely to use referrals in the job search process and focus on the effect of referrals on wages. Most empirical studies generally agree that $30-60 \%$ of new hires find jobs through personal contacts. However, there is no agreement in this literature concerning the effect of referrals on wages. Whereas some authors argue that the informal channel of search leads to wage penalties for workers, others emphasize the importance of networks in the creation of good matches, associated with wage premiums ${ }^{1}$. This contradicting empirical evidence, which can be well described as a "referral puzzle", is summarized in Pelizzari (2010) who writes that "... in the European Union premiums and penalties to finding jobs through personal contacts are equally frequent and are of about the same size". To shed some light on this issue from a theoretical perspective we suggest to distinguish between the two types of social contacts - family and professional ties - and allow for the endogenous search intensity of workers and firms.

The ingredients of the model are as follows. Firms are homogeneous at the stage of a vacancy, but workers differ in their productivity which we also interpret as a level of skills or ability. There are two types of social contacts. Family contacts are exogenous in the model and serve as a residual method of search. In addition, every worker has a fixed number of professional contacts $^{2}$. Ioannides and Datcher Loury (2004) report that acquired social contacts develop along dimensions such as race, ethnicity, religious affiliation and education. Therefore, in our model we assume a strong degree of network homophily along the productivity or the skill dimension. Thus, the job-finding rate through the network of professional contacts is skill-specific. In this setup, we distinguish between the three job search channels: formal applications to posted vacancies and two informal channels - through family and professional networks. Both informal channels of search are costless for workers, but preparing a formal application is associated with a positive effort cost. Moreover, through the endogenous group-specific advertising intensity firms can direct their network search towards particular groups of incumbent employees. This contrasts with the formal search channel, which is random and undirected.

There are two key predictions of the model which can be described in the following way:

- The model exhibits a strong U-shape referral hiring pattern: workers in the right (left) tail of the productivity distribution have the highest propensity of finding a job with a help of professional (family) contacts, whereas the formal channel of search is mostly utilized by workers in the middle range of the distribution;

- When the two types of social contacts are separated, family contacts are associated with wage penalties, whereas referrals from professional contacts are associated with wage premiums. The average effect of referrals on wages is ambiguous and depends on the relative proportions of high and low productivity workers in the population.

\footnotetext{
${ }^{1}$ Wage penalties are reported in Bentolila, Michelacci and Suarez (2010), Delattre and Sabatier (2007), Pistaferri (1999) and Addison and Portugal (2002). Wage premiums are supported by Staiger (1990), Simon and Warner (1992), Granovetter (1995) and Margolis and Simonnet (2003).

${ }^{2}$ The importance of relatives for job search is reported by Corac and Piraino (2011) and Kramarz and Nordstrom-Skans (2011). For the role of former co-workers see Cingano and Rosolia (2012) and Glitz (2013).
} 
To the best of our knowledge there are no other studies that can generate these two predictions in a unified theoretical framework. First, we explain the mechanism which is generating the U-shape. Every wage is an outcome of bargaining between the firm and the worker. Therefore, wages are increasing in the productivity, which is observable to the firm. With respect to the formal search channel, unemployed workers trade off the cost and the gain of effort, so the optimal search intensity is increasing in the productivity of the worker. Thus the least productive group of workers has a lowest job-finding rate associated with a formal channel. In addition, the probability of getting a job via professional referrals is also low for these workers due to a larger share of unemployed contacts in their networks. This latter finding is explained by the fact that the equilibrium unemployment rate is decreasing with a productivity of the worker. Low types are then relying on their family to find a job, which is a method of last resort in the model.

Another implication of bargaining is that firms' profits are increasing in the productivity of the hired applicant. As the labour market exhibits a strong degree of skill homophily, firms correctly anticipate a high productivity applicant if they approach an incumbent employee of the same type. Such a behavior of firms is based on the belief that people tend to refer others who are similar to themselves (Saloner, 1985; Montgomery, 1991; Galenianos, 2012). Since the advertising effort of firms is group-specific and endogenous, it is optimal for them to direct their search at incumbent workers of higher types. For unemployed workers this means that the job-finding rate through the network of professional contacts is increasing in the worker's type. So the formal channel of search is becoming less relevant for the more productive groups of applicants and is mostly utilized by workers in the middle range of the distribution. This explains the U-shape of the referral hiring pattern in the model. Specifically, in a benchmark calibration of the model, the fraction of workers relying on referrals falls down from $100 \%$ to $38 \%$ in the middle of the distribution and rises again to $67 \%$ for the most productive workers.

Second, we analyze the effect of referrals on wages. As low productivity types are more likely to rely on family contacts, the equilibrium wage distribution of workers who used this channel is first order stochastically dominated by the distribution of workers who used a formal method. So the model predicts wage penalties associated with family contacts. In the benchmark calibration of the model the penalty is equal to $6 \%$. High productivity workers are more likely to rely on professional contacts. Thus the equilibrium earnings distribution corresponding to this channel first order stochastically dominates the distribution of workers who used a formal method. Hence the network of professional contacts is associated with wage premiums. In the benchmark calibration of the model the premium is equal to $10 \%$. Intuitively, wage penalties/premiums arise due to the self-selection of workers into a specific method of search and are robust to different shapes of the skill/productivity distribution. This is different for the average effect of referrals on wages. To illustrate this result we perform comparative statics analysis with respect to the shift parameter of the skill distribution. Then the average wage effect of referrals is negative (positive) in a labour market with a large fraction of low (high) types.

Next, we review the empirical support of these predictions. In a recent paper Brown et al. (2012) estimate the relationship between the educational level and the probability of getting a job offer. First they find that referrals have a significantly greater impact on the overall probability of offer receipt for positions with lower education requirements. This is true for high school diplomas and associate's degrees. At the same time they report that referrals have 
a significantly larger positive impact on the probability of being interviewed for positions with a graduate rather than college degree requirement. The authors conclude that referral effects on hiring have a significant U-shaped relationship with a skill level in the United States. This finding is also supported for the Netherlands in an earlier paper by Boxman et al. (1991), which was the first study to make this observation.

The second prediction of our model is supported by Capellari and Tatsiramos (2013) for the United Kingdom and Meliciani and Radicchia (2011) for Italy. Specifically, Capellari and Tatsiramos (2013) report that high skilled workers with a better network quality of non-relatives experience wage premiums in the British labour market. In contrast, low skilled workers with a better network quality of relatives are more likely to experience a wage penalty associated with a referral. Likewise, empirical evidence presented in Meliciani and Radicchia (2011) suggests that workers entering the labour market via professional contacts enjoy a wage bonus, whereas those recruited via referrals from family and close friends receive on average lower wages. For Italy a similar result is also reported in an earlier study by Sylos Labini (2004). Some indirect evidence in favor of our model is also provided by Kramarz and Nordstrom-Skans (2011) and Hensvik and Nordstrom-Skans (2013) for Sweden. For example, the former study finds that school graduates of lower ability are more likely to find a job through their parents but with a wage penalty. In contrast, Hensvik and Nordstrom-Skans (2013) report that incumbent workers of high ability (test score) are more likely to be linked to entering workers. Furthemore, the abilities of incumbent workers are reflected in the higher starting wages of linked entrants.

Finally, we consider the overall effect of referrals on wages without separating into family and professional contacts. Our model predicts that the average effect is positive if the proportion of high productivity workers in the population is relatively high, overwise it is negative. This finding may serve as an explanation of the mixed empirical evidence on the average wage effect of referrals. For example, Staiger (1990), Simon and Warner (1992) and Granovetter (1995) report that referrals are associated with wage premiums in the United States. The hypothesis of wage premiums is also supported by Margolis and Simonnet (2003) and Goos and Salomons (2007) for France and the United Kingdom. In contrast, Bentolila, Michelacci and Suarez (2010) report wage penalties in the United States and the European Union. This result is supported by Delattre and Sabatier (2007), Pistaferri (1999) as well as Addison and Portugal (2002) for France, Italy and Portugal respectively.

Apart from empirics, our study is also related to a number of theoretical papers analyzing the role of social networks. Early economic studies on social contacts include Simon and Warner (1992), Montgomery (1991, 1992, 1994) and Mortensen and Vishwanath (1994). Both Simon and Warner (1992) and Montgomery (1991) emphasize that referrals reveal the quality of the match to the employer and therefore should have a positive effect on wages. This result is similar to the positive wage effect of professional referrals in our model, however the possibility to rely on family contacts is not included in the early studies. The first and only paper where both types of contacts - family and professional - are explicitly included in a theoretical model is a study by Sylos Labini (2004). This paper shows that workers who find their job through professional referrals earn on average higher wages, whereas workers who are recommended by their relatives earn lower wages. This finding is inline with the second prediction of our model, but it does not generate the first prediction of the U-shape referral hiring pattern. 
Recent theoretical studies generating wage premiums associated with referrals include Kugler (2003), Ioannides and Soetevent (2006) and Galenianos (2012). Specifically, Kugler (2003) finds that the benefit of using referrals for firms is that they lower monitoring costs, because workers can exert peer pressure on coworkers. As a result, firms relying on referrals find it cheaper to elicit effort by paying efficiency wages than firms using formal hiring methods. Ioannides and Soetevent (2006) support this result by showing that better connected workers experience lower unemployment rates and receive higher wages. Our model also has the property that the proportion of unemployed workers in the network of contacts is decreasing with the producitivity. Moreover, this feedback effect is reinforcing the fact that high productivity workers are more likely to rely on the network of professional contacts when searching for jobs. However, our model also allows for the possibility to get help from family contacts which is not a subject of the aforementioned research studies.

The group of papers that can generate wage penalties in a theoretical framework includes Bentolila et al. (2010) as well as Ponzo and Scoppa (2010). Ponzo and Scoppa (2010) argue that recruiters may favor low ability family ties over more talented applicants. This is the idea of favoritism in the recruiting process. Bentolila et al. (2010) find that social contacts can generate a mismatch between occupational choices and productive advantages of workers. This is particularly true for workers who failed to find a job in their occupation and followed a recommendation of a close family member. Horvath (2013) extends the mismatch result of Bentolila et al. (2010). As the probability that ties connect similar agents (homophily) increases, the mismatch level decreases in his model. Moreover, if this probability is suciently high, networks provide good matches at higher rate upon arrival than the formal market. Therefore, referrals can generate wage premiums if the homophily level in the society is high. Otherwise, if social contacts are strongly heterogeneous, the effect of referrals on wages may be negative due to a stronger mismatch between the skill of the worker and the type of the job.

Other theoretical papers which can explain wage premiums/penalties depending on the parameters of the labour market are Sylos-Labini (2004), Tumen (2013) and Zaharieva (2012). Tumen (2013) considers a population of workers heterogeneous with respect to the cost of maintaining connections. In his model well integrated workers with low costs have higher reservation wages and are able to bargain higher wages. Conversely, workers with higher costs accept wages below the market level. Zaharieva (2012) investigates the role of referrals in a matching model with on-the-job search. On the one hand, in her model better connected workers bargain higher wages for a given level of job-related productivity. This is the positive effect of outside opportunities on wages. On the other hand, employees rationally accept job offers from more productive employers and forward other offers to the unemployed contacts. Therefore, job offers transmitted through social contacts are biased in the direction of less productive employers. This selection mechanism can generate a negative effect of referrals on wages. To sum up, both papers by Tumen (2013) and Zaharieva (2012) can generate wage penalties or premiums in wages associated with social contacts, however, in each paper the mechanism is different from the present study.

The paper is organized as follows. Section 2 explains notation and the general economic environment. In section 3 we investigate the decisions of workers and firms and explain their choice of the search intensity. Section 4 illustrates our theoretical results by means of a numerical example, while section 5 concludes the paper. 


\section{Labour market modeling framework}

The labour market is characterized by the following properties. There is a continuum of infinitely lived risk neutral workers and firms discounting future at a common discount rate $r$. Firms are homogeneous, while workers have heterogeneous skills and abilities. Worker's ability and skills are reflected in his/her productivity $y_{i}, i=1 . . p$ which follows a discrete probability distribution $f_{i}$, such that $\sum_{i=1}^{p} f_{i}=1$. Workers are perfectly informed about their productivity $y_{i}$, while firms with open vacancies are aware of the productivity distribution $f_{i}, \forall i=1$..p. At the same time firms learn the exact productivity of the worker upon the match, so there is no asymmetric information in the model. The highest productivity $y_{p}$ is set to 1 , while the lowest productivity $y_{1}$ is equal to the unemployment benefit $b$.

Every worker can be either employed and producing output $y_{i}$ or unemployed and searching for a job. Let $u_{i}$ denote the mass of unemployed workers with productivity $y_{i}$ and $e_{i}$ - the mass of corresponding employees, so that $e_{i}+u_{i}=f_{i}$, since the total measure of workers is normalized to 1 . There are three search channels in the labour market. First, unemployed workers can find a job by sending regular applications to open vacancies, this is the formal channel of job search with an endogenous job-finding rate $\phi(s)$. Variable $s$ is the individual search effort of workers and may differ across agents belonging to different productivity groups, i.e. $s_{i}$. The formal channel of search is costly in terms of effort, since it requires preparing and sending job applications. However, a more intensive job search is associated with a higher probability of finding employment. Let $C(s)=s^{2} / c$ denote the effort cost function, which is identical for all workers in the market.

Further, let all workers have an equal number of professional contacts $n>0$. Employed workers provide referrals and transmit vacancy information to the unemployed members of their network, this is the second channel of job search. To simplify the model we assume that professional contacts are only formed among workers with the same productivity level $y_{i}$. Therefore, the job-finding rate through the network of professional contacts is skill-specific and is denoted by $\lambda_{i}$. Empirical support for this assumption comes from the observation of strong homophily in social networks reported in Rivera, Soderstrom and Uzzi (2010). In addition, professional networks are largely composed of former coworkers, therefore these contacts are specific to a particular skill-group. Finally, $\lambda_{0}$ is a constant probability of hearing about a job from family members which is a third search channel in the model. Job referrals from professional contacts and family are the informal methods of search and are costless for workers.

Firms are free to enter the labour market by opening a new vacancy. Open vacancies are associated with a flow cost $z$ on the side of the firm which can be understood as a cost of capital depreciation as well as expenses from hiring and interviewing activities. Formal matching between unemployed workers and vacancies is random and discussed below. To model the process of network matching we extend the approach of Cahuc and Fontaine (2009) and assume that firms make a random draw from the pool of incumbent employees with an advertising intensity $a$ per unit time. However, in our model the advertising intensity $a$ is endogenous and can be specific to a given group of employees, i.e. $a_{i}$. Intuitively, $a_{i}$ is an effort level with which the manager of an open vacancy is addressing an incumbent employee of type $i$ to refer one of his/her contacts. This extension allows firms to direct their search more intensively towards the more 
productive group of workers. The advertising search intensity $a$ is costly for firms with a cost function $K(a)=a^{2} / k$. Note that the advertising intensity $a_{i}$ is chosen after the match with an employee and so the cost $K\left(a_{i}\right)$ is unrelated to the cost $K\left(a_{j}\right)$ for $i \neq j$. If the job position is filled with a worker, the firm obtains a flow profit $y_{i}-w_{i}$, where the wage $w_{i}$ is bargained between the firm and the worker upon hiring. We use the Nash bargaining rule to determine wages. Every filled job can be destroyed for exogenous reasons at rate $\delta$.

Let $m(x, v)$ denote a matching function between workers and firms, where $v$ is the number of open vacancies and $x$ is the number of searching workers in efficiency units (either unemployed or employed, transmitting job offers to their unemployed contacts). Following the approach of Gautier et al. (2010) we assume that the matching technology is quadratic, that is $m(x, v)=x v$. This approach has been frequently used in the search literature, for example, Teulings and Gautier (2004) provide a number of explanations why this technology may be the most adequate assumption in a model with worker heterogeneity. The main reason is that this technology avoids congestion externalities between different worker types and jobs.

Consider matching between unemployed workers and open vacancies. The total number of searching unemployed workers weighted by their search intensity is given by $x=\sum s_{i} u_{i}$, so the number of contacts created through the formal method of search is $v \sum s_{i} u_{i}$. However, only proportion $s_{i} u_{i} / \sum s_{i} u_{i}$ of these contacts are the matches between open vacancies and unemployed workers of type $y_{i}$. Therefore the number of matches between open vacancies and unemployed workers of type $y_{i}$ is given by:

$$
v \sum s_{i} u_{i} \cdot \frac{s_{i} u_{i}}{\sum s_{i} u_{i}}=v s_{i} u_{i}
$$

This means that the job-finding rate through the formal channel of search is equal to $\phi_{i} \equiv \phi\left(s_{i}\right)=$ $v s_{i} u_{i} / u_{i}=v s_{i}$ and is increasing in the total number of vacancies $v$ and the individual search intensity of unemployed workers $s_{i}$. In addition, from the perspective of firms, the probability of filling a job through the formal channel with a worker of type $y_{i}$ is $\phi_{i} u_{i} / v=s_{i} u_{i}$.

Next consider matching between employed workers and open vacancies. The total number of employees in efficiency units is given by $x=\sum a_{i} e_{i}$, so the number of contacts between vacancies and employees with productivity $y_{i}$ is equal to $v \sum a_{i} e_{i}$. However, only a fraction $a_{i} e_{i} / \sum a_{i} e_{i}$ of these contacts are the matches between open vacancies and employees of type $y_{i}$. Every contacted employed worker transmits vacancy information to exactly one randomly chosen unemployed social contact out of a pool of $n$ contacts. Here we assume that job information is only transmitted to the direct social links, so the job offer is lost if all $n$ contacts are employed. The probability of being employed for an arbitrary worker of type $y_{i}$ is equal to $1-\mu_{i}$, where $\mu_{i} \equiv$ $u_{i} / f_{i}$ is the unemployment rate in a group of workers with productivity $y_{i}$. So the probability that all $n$ contacts of the employee are also employed is equal to $\left(1-\mu_{i}\right)^{n}$. This means that the number of matches between vacancies and unemployed workers of type $y_{i}$ through the network of contacts is given by:

$$
v \sum a_{i} e_{i} \cdot \frac{a_{i} e_{i}}{\sum a_{i} e_{i}} \cdot\left[1-\left(1-\mu_{i}\right)^{n}\right]=v a_{i} e_{i}\left[1-\left(1-\mu_{i}\right)^{n}\right]
$$

where expression in the square bracket is the probability of having at least one unemployed 
contact out of $n$. The individual job-finding rate through the first informal search channel (professional contacts) is then equal to:

$$
\lambda_{i}=v a_{i} \frac{e_{i}}{u_{i}}\left[1-\left(1-\mu_{i}\right)^{n}\right]=v a_{i} \frac{1-\mu_{i}}{\mu_{i}}\left[1-\left(1-\mu_{i}\right)^{n}\right]
$$

Note that $\lambda_{i}$ is increasing in the number of vacancies $v$ and the number of social contacts $n$. Moreover, a more intensive search by firms directed at workers of type $y_{i}$, that is a higher $a_{i}$, is raising the probability of finding a job for an unemployed worker of this type. From the perspective of firms, the flow probability of filling a job with a professional contact of an incumbent employee of type $y_{i}$ is equal to $\lambda_{i} u_{i} / v=a_{i} e_{i}\left[1-\left(1-\mu_{i}\right)^{n}\right]$.

\section{Analysis of the model}

\subsection{Workers and their choice of search effort}

Let $U_{i}\left(W_{i}\right)$ denote the present value of being unemployed (employed) for the worker with productivity $y_{i}, i=1$..p. The asset value of unemployed workers of type $y_{i}$ is given by:

$$
r U_{i}=b+\left(\lambda_{0}+\lambda_{i}\right)\left(W_{i}-U_{i}\right)+v \max _{s}\left[s\left(W_{i}-U_{i}\right)-\frac{1}{c} s^{2}\right]
$$

and reflects simultaneous availability of the three job search channels discussed above. The rent from employment is independent of the search channel and is denoted by $R_{i} \equiv\left(W_{i}-U_{i}\right)$. Workers choose costly effort $s_{i}$ to maximize the present value of unemployment $U_{i}$, therefore the optimal level of search effort $s_{i}$ obtains at the point where the marginal gain $\left(W_{i}-U_{i}\right)$ is equal to the marginal cost $C^{\prime}(s)$ :

$$
s_{i}=0.5 c\left(W_{i}-U_{i}\right)=0.5 c R_{i}
$$

Therefore, the asset value of unemployment can be rewritten as:

$$
r U_{i}=b+\left(\lambda_{0}+\lambda_{i}\right) R_{i}+0.25 c v R_{i}^{2}
$$

Further, the asset value of employed workers of type $y_{i}$ is given by:

$$
r W_{i}=w_{i}-\delta\left(W_{i}-U_{i}\right)
$$

and so the worker rent from employment is equal to the discounted net present value of earnings: $R_{i}=\left(w_{i}-r U_{i}\right) /(r+\delta)$. Combining this and equation (2) allows us to derive the optimal search effort $s_{i} \equiv s\left(\lambda_{i}, w_{i}\right)$. These results are summarized in Lemma 1:

Lemma 1: Consider workers with productivity $y_{i}$. The optimal job-finding rate $\phi\left(s_{i}\right)=v s_{i}$ through the formal channel of search is given by:

$$
v s_{i}=\sqrt{\left(r+\delta+\lambda_{0}+\lambda_{i}\right)^{2}+\left(w_{i}-b\right) c v}-\left(r+\delta+\lambda_{0}+\lambda_{i}\right)
$$

The optimal search intensity $s\left(\lambda_{i}, w_{i}\right)$ is increasing in the wage $w_{i}$ but decreasing in $\lambda_{i}$, which is a job-finding rate through professional contacts. 


\section{Proof: Appendix I.}

Lemma 1 shows that a higher wage $w_{i}$ would motivate workers to exert more effort when applying for jobs. On the contrary, a higher job-finding rate through professional contacts $\lambda_{i}$ improves the outside opportunities of workers, so the total rent from a job $R_{i}$ is reduced. A lower rent then has a disincentive effect on the intensity of job search.

\subsection{Firms and the wage determination}

From the perspective of firms, let $J_{i}$ be the asset value of a job, filled with a worker of type $y_{i}$, and $V$ be the present value of the open vacancy. We will come back to the determination of $V$ in section 3.5. Once matched firms observe the productivity of the applicant, so $J_{i}$ is given by:

$$
r J_{i}=y_{i}-w_{i}-\delta\left(J_{i}-V\right)
$$

The equilibrium wages are determined by means of Nash bargaining with a disagreement-whilebargaining state $U_{i}^{D}$ for type $y_{i}$ worker and with $\alpha \in(0,1)$ being the workers' bargaining power, for example, as in Gautier (2002) and Hall and Milgrom (2008). This approach is close to the bargaining model with a risk of a negotiation breakdown by Binmore et al. (1986) and allows to simplify the model, while not influencing qualitatively the results. An unemployed worker gets a present value $U_{i}^{D}$ during the disagreement time, while the employer obtains a present value $V_{i}{ }^{D}$. We assume that during the time of negotiation neither the worker nor the firm continue searching for other partners. This is intuitive since there are no reasons for agents to exert costly search effort when they are already in the process of bargaining with a prospective partner. This means that neither the worker nor the firm pays the search cost during the period of negotiation, however, the worker still receives the unemployment benefit from the state. Thus, $U_{i}^{D}$ and $V_{i}^{D}$ can be written as:

$$
r U_{i}^{D}=b+\delta\left(U_{i}-U_{i}^{D}\right) \quad r V_{i}^{D}=\delta\left(V-V_{i}^{D}\right)
$$

These equations imply that vacancies have the same probability $\delta$ of being destroyed during the bargaining as do existing jobs. Moreover, if the bargaining process breaks down for an exogenous reason, the worker becomes unemployed with a present value $U_{i}$ and the position remains vacant with a present value $V$. The solution is the wage $w_{i}$ maximizing the Nash objective function $\left(W_{i}-U_{i}^{D}\right)^{\alpha}\left(J_{i}-V_{i}^{D}\right)^{1-\alpha}$ which can be written as:

$$
\max _{w_{i}}\left(\frac{w_{i}+\delta U_{i}}{r+\delta}-\frac{b+\delta U_{i}}{r+\delta}\right)^{\alpha}\left(\frac{y_{i}-w_{i}+\delta V}{r+\delta}-\frac{\delta V}{r+\delta}\right)^{1-\alpha} \Rightarrow w_{i}=\alpha y_{i}+(1-\alpha) b
$$

This maximization problem shows that the wage is a weighted average between the unemployment benefit $b$ and the productivity $y_{i}$. Therefore, wages are heterogeneous in the economy and resemble the productivity distribution in the population of workers. Let $g_{i}$ denote the equilibrium distribution of wages, such that $\sum g_{i}=1$. It is then given by:

$$
g_{i}=\frac{e_{i}}{e}=\frac{f_{i}\left(1-\mu_{i}\right)}{\sum f_{i}\left(1-\mu_{i}\right)}=\frac{f_{i}\left(1-\mu_{i}\right)}{1-\sum f_{i} \mu_{i}}
$$


where $e=1-\sum f_{i} \mu_{i}$ is the equilibrium employment rate in the economy. Intuitively, if the employment rate of some worker group is smaller than the average, i.e. $\left(1-\mu_{i}\right)<\left(1-\sum f_{i} \mu_{i}\right)$, then this group is underrepresented in the earnings distribution compared to the initial productivity density $f_{i}$. The opposite holds when the employment rate of some worker group is larger than the average, so this group is overrepresented.

\subsection{Type-specific unemployment rates}

Consider workers with productivity $y_{i}$. The unemployment rate $\mu_{i}=u_{i} / f_{i}$ can be found from the steady-state equation for unemployed workers. It can be written as:

$$
0=\dot{u}_{i}=\delta\left(f_{i}-u_{i}\right)-\left(\lambda_{0}+\lambda_{i}+s_{i} v\right) u_{i}
$$

and reflects the fact that the inflow into and the outflow out of unemployment are equalized in the steady state. Thus, the equilibrium unemployment rate $\mu_{i}$ is equal to:

$$
\mu_{i}=\frac{\delta}{\lambda_{0}+s_{i} v+\lambda_{i}+\delta}=\frac{\delta}{\sqrt{\left(\delta+\lambda_{0}+\lambda_{i}\right)^{2}+\alpha\left(y_{i}-b\right) c v}} \quad \Rightarrow \quad \mu_{i}=\mu\left(\lambda_{i}, y_{i}\right)
$$

where the second equality is obtained for the limiting case $r \rightarrow 0$ to simplify the exposition. Hence the equilibrium unemployment rate can be expressed as a function of the job-finding rate $\lambda_{i}$ and the productivity $y_{i}$. Next, consider a partial relationship between $\mu_{i}$ and $\lambda_{i}$ for a fixed productivity $y_{i}$. A higher probability of finding a job through professional contacts (that is a higher $\left.\lambda_{i}\right)$, has an indirect disincentive effect on the search intensity $s\left(\lambda_{i}, y_{i}\right)$. Consequently, a lower level of search effort through the formal channel raises the equilibrium unemployment rate $\mu_{i}$. This is an indirect effect which is operating through the outside opportunities of workers. At the same time a higher $\lambda_{i}$ reduces the unemployment rate $\mu_{i}$. This is a direct effect since more unemployed workers find jobs by means of referrals. Equation (7) shows that the direct effect is dominating and describes a negative relationship between the unemployment rate $\mu_{i}$ and the job-finding rate through professional contacts $\lambda_{i}$ :

$$
\frac{\partial \mu\left(\lambda_{i}, y_{i}\right)}{\partial \lambda_{i}}<0 \quad \lim _{\lambda_{i} \rightarrow 0} \mu_{i}=\frac{\delta}{\sqrt{\left(\delta+\lambda_{0}\right)^{2}+\alpha\left(y_{i}-b\right) c v}} \equiv \bar{\mu}_{i}>0 \quad \lim _{\lambda_{i} \rightarrow \infty} \mu_{i}=0
$$

This is illustrated in figure 1 , where $\bar{\mu}_{i}$ denotes the upper limit of the unemployment rate $\mu_{i}$ for a given fixed level of $y_{i}$. The corresponding curve is denoted by (UC).

Further, recall from section 2 that the job-finding rate by means of referrals $\lambda_{i}$ depends on the unemployment rate in the network $\mu_{i}$. In particular, it holds that:

$$
\lambda_{i}=v a_{i} \frac{1-\mu_{i}}{\mu_{i}}\left[1-\left(1-\mu_{i}\right)^{n}\right] \quad \Rightarrow \quad \lambda_{i}=\lambda\left(\mu_{i}, a_{i}\right)
$$

If more workers of a given type are employed (that is a lower $\mu_{i}$ ) the possibilities for firms to communicate with this group of employees arise more frequently. And hence the contact rate between firms and unemployed workers of type $y_{i}$ is increased. But on the other hand, a lower unemployment rate $\mu_{i}$ implies a lower number of unemployed contacts in the network and therefore, a lower probability that the contacted employee will recommend someone for a job 

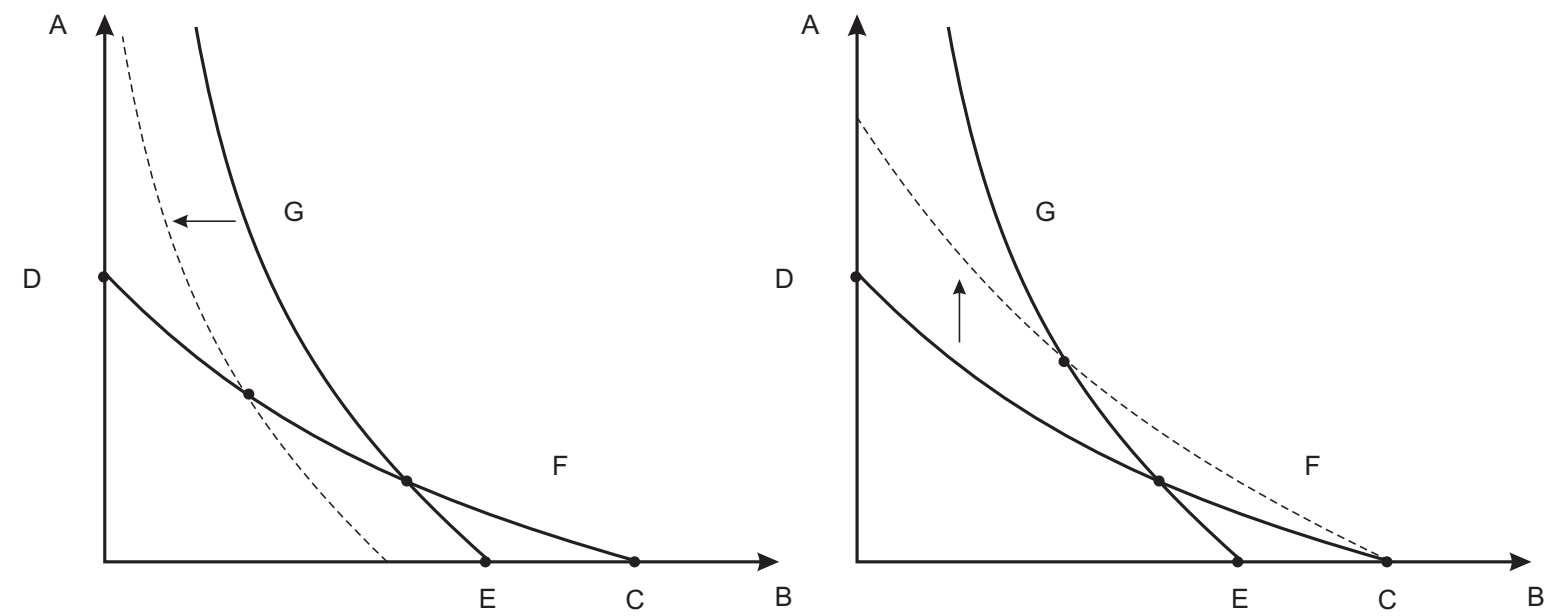

Figure 1: Intersection between $\mu(\lambda, y)$ and $\lambda(\mu, a)$ for a given advertising intensity $a$ and a given productivity $y$. Left panel: changes in $\lambda(\mu, a)$ and $\mu(\lambda, y)$ given a positive shift in $y$. Right panel: changes in $\lambda(\mu, a)$ and $\mu(\lambda, y)$ given a positive shift in $a$.

$\left[1-\left(1-\mu_{i}\right)^{n}\right]$. Lemma 2 shows that the indirect network effect is dominated by the direct effect of a higher contact rate between firms and unemployed workers and so equation (8) describes a negative relationship between variables $\lambda_{i}$ and $\mu_{i}$. The corresponding curve is denoted by (NC).

Lemma 2: For a given advertising intensity $a_{i}$, a lower unemployment rate $\mu_{i}$ in a group of workers with productivity $y_{i}$ implies a higher job-finding rate through the informal channel of search $\lambda_{i}$ :

$$
\frac{\partial \lambda_{i}\left(\mu_{i}, a_{i}\right)}{\partial \mu_{i}}<0 \quad \lim _{\mu_{i} \rightarrow 0} \lambda_{i}=n v a_{i} \quad \lim _{\mu_{i} \rightarrow 1} \lambda_{i}=0
$$

Proof: Appendix II.

Based on the results from lemma 2, figure 1 shows that there is a unique intersection between the curves $\mu\left(\lambda_{i}, y_{i}\right)$ and $\lambda\left(\mu_{i}, a_{i}\right)$. This implies that $\mu_{i}$ is an implicit function of the productivity $y_{i}$ and the advertising intensity $a_{i}$, formally (for $r \rightarrow 0$ ):

$$
\mu_{i}=\frac{\delta}{\sqrt{\left(\delta+\lambda_{0}+\lambda\left(\mu_{i}, a_{i}\right)\right)^{2}+\alpha\left(y_{i}-b\right) c v}} \quad \Rightarrow \quad \mu_{i}=m\left(y_{i}, a_{i}\right)
$$

To analyze the intuitive implications of this relationship consider workers with a higher productivity $y_{i}$. More productive workers expect to get a higher wage $w_{i}$, so the gain from finding a job is increasing in the productivity. This means that more able workers invest more effort in writing applications and preparing for a job interview. More intensive job search through the formal channel improves the job-finding rate $v s\left(\lambda_{i}, w\left(y_{i}\right)\right)$ and so the unemployment rate $\mu\left(\lambda_{i}, y_{i}\right)$ is reduced for every value of $\lambda_{i}$. On figure 1 this is illustrated by the left-ward shift of the curve (UC) on the left panel. Since productivity does not enter directly into the job-finding rate through the network, there is no shift of the curve (NC). This means that the unemployment rate is unambiguously lower in more productive worker groups. Consequently a larger proportion of employees facilitates informal matching between open vacancies and unemployed workers and therefore the probability of finding a job by recommendation is increasing. These results are summarized in lemma 3 : 
Lemma 3 Let $r \rightarrow 0$. For a given advertising intensity $a_{i}$, the equilibrium unemployment rate $\mu_{i}=m\left(y_{i}, a_{i}\right)$ is lower in more productive worker groups. Further, for every productivity group $y_{i}$, the equilibrium unemployment rate falls with a higher search effort by firms, formally:

$$
\frac{\partial m\left(y_{i}, a_{i}\right)}{\partial y_{i}}<0 \quad \frac{\partial m\left(y_{i}, a_{i}\right)}{\partial a_{i}}<0 \quad \lim _{a_{i} \rightarrow 0} m\left(y_{i}, a_{i}\right)=\lim _{\lambda_{i} \rightarrow 0} \mu\left(\lambda_{i}, y_{i}\right)=\bar{\mu}_{i}
$$

Proof: Appendix III.

In addition, lemma 3 describes consequences of a higher search intensity by firms $a_{i}$. If firms exert more effort in contacting their employees, then the probability of finding a job by means of a referral is increased for every unemployment rate $\mu_{i}$. On figure 1 this is illustrated by the up-ward shift of the curve (NC) on the right panel. Since advertising intensity does not enter directly the unemployment equation, there is no shift of the curve (UC). This means that the job finding rate $\lambda_{i}$ is unambiguously higher and the equilibrium unemployment rate is reduced.

\subsection{Endogenous advertising rate for referral hiring}

Let us now consider the optimal behavior of a firm with an open vacancy. Apart from formal applications the firm may also fill its vacancy through the informal channel of search. In particular, the firm should choose the optimal advertising intensity $a_{i}$ for every worker type $y_{i}$. Intuitively, at rate $a_{i}$ the firm is asking type- $y_{i}$ incumbent employees whether they can recommend a friend for the open vacancy. Similarly to the effort choice of the unemployed, there is a gain and a cost from advertising activity. The expected firm rent from contacting the incumbent employee of type $y_{i}$ is equal to $a\left(1-\left(1-\mu_{i}\right)^{n}\right)\left(J_{i}-V\right)$, which is the probability that the job offer will be transmitted to the unemployed worker of this type times the present value of profits. This gives rise to the following maximization problem:

$$
\max _{a}\left[a\left(1-\left(1-\mu_{i}\right)^{n}\right)\left(J_{i}-V\right)-\frac{1}{k} a^{2}\right]
$$

The optimal $a_{i}$ is, thus, given by:

$$
a_{i}=0.5 k\left(1-\left(1-\mu_{i}\right)^{n}\right)\left(J_{i}-V\right) \quad \text { where } \quad J_{i}-V=\frac{(1-\alpha)\left(y_{i}-b\right)-r V}{r+\delta}
$$

This first order condition defines the level of advertising $a_{i}$ as a function of $\mu_{i}$ and $y_{i}$, that is $a_{i}=a\left(\mu_{i}, y_{i}\right)$. Therefore, for a given $y_{i}$, firms exert more advertising effort if they expect a higher proportion of unemployed workers in the network of the incumbent employee. In the following we consider the economy in the steady-state with a free-entry of firms, which means that $V=0$. Figure 2 shows equilibrium for advertising effort and unemployment. Recall that $\mu_{i}=m\left(y_{i}, a_{i}\right)$ slopes down in the space $(\mu, a)$ : finding jobs becomes easier for unemployed workers if firms increase their advertising activities. Let this curve be denoted by (MA) (see figure 2). Equation (9) is the advertising curve and slopes up, let it be denoted by (AC). Group-specific equilibrium $\left(\mu\left(y_{i}\right), a\left(y_{i}\right)\right)$ is at the intersection of the two curves and it is unique.

Next compare the equilibrium vector of variables $\left(\mu\left(y_{i}\right), a\left(y_{i}\right)\right)$ across different productivity groups. On the one hand, more productive workers exert more effort in sending applications and preparing for the job interview, so their unemployment is lower for any advertising intensity 


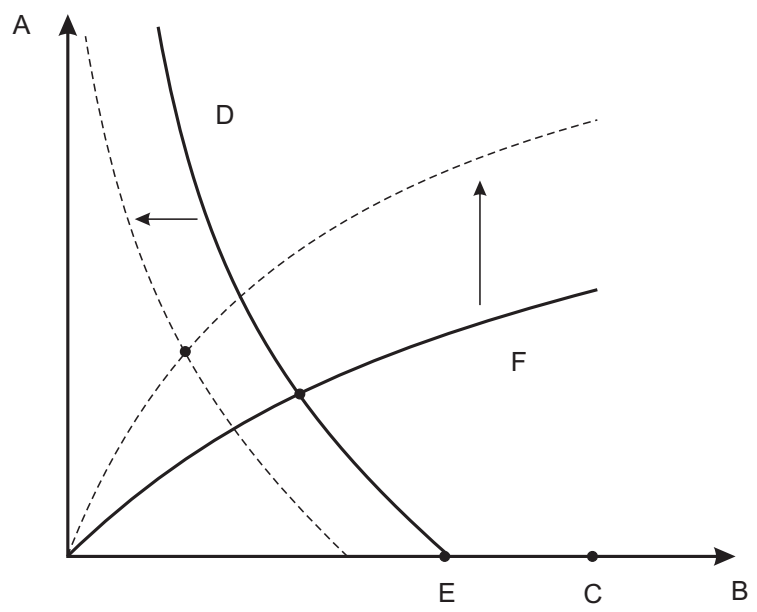

Figure 2: Determination of the type-specific unemployment rate $\mu(a, y)$ with the endogenous advertising intensity of firms $a(\mu, y)$. Arrows indicate higher values of $y$.

$a_{i}$. On figure 2 this is illustrated by the inward shift of the curve (MA). On the other hand, for a given $\mu_{i}$, firms expect to earn higher profits from more productive network applicants, and so their advertising effort is higher when the firm is communicating with a more productive incumbent employee. This implies an upward shift of the advertising curve (AC) since firms' effort is increasing for every level of the unemployment rate $\mu_{i}$. Considering both changes as a combination shows that the equilibrium unemployment rate is lower in more productive worker groups. This result is described in proposition 1:

Proposition 1: Let $r \rightarrow 0$. (i) The group-specific equilibrium unemployment rate $\mu_{i}$ is decreasing in the productivity $y_{i}$. (ii) The job-finding rate $\lambda_{i}$ and the network advertising intensity $a_{i}$ are both increasing in $y_{i}$ if the elasticity of referral probability $\rho\left(y_{i}\right) \equiv\left[1-\left(1-\mu\left(y_{i}\right)\right)^{n}\right]$ with respect to the productivity $y_{i}$ is less than 1, formally:

$$
-\frac{\partial \rho\left(y_{i}\right)}{\partial y_{i}} \cdot \frac{y_{i}-b}{\rho\left(y_{i}\right)}=-\frac{n\left(1-\mu\left(y_{i}\right)\right)^{n-1}}{1-\left(1-\mu\left(y_{i}\right)\right)^{n}} \cdot \frac{\partial \mu\left(y_{i}\right)}{\partial y_{i}} \cdot\left(y_{i}-b\right)<1
$$

Proof: Appendix IV.

Proposition 1 shows that there are two counteracting effects of $y_{i}$ on the network advertising intensity $a\left(y_{i}\right)$. On the one hand, firms anticipate higher profits from more productive network applicants and direct their search towards worker groups with a higher $y_{i}$. But on the other hand, the equilibrium unemployment $\mu\left(y_{i}\right)$ is decreasing in $y_{i}$ which means that the average proportion of unemployed workers in the network is lower in less productive worker groups. From the perspective of firms this means a lower probability of referral hiring. Condition (10) then implies that the first direct effect of higher profits is dominating if the equilibrium unemployment rate is sufficiently inelastic.

Finally, the job-finding rate through professional contacts $\lambda\left(y_{i}\right)$ can be now rewritten as:

$$
\lambda\left(y_{i}\right)=\frac{a\left(y_{i}\right) v\left(1-\mu\left(y_{i}\right)\right)}{\mu\left(y_{i}\right)} \rho\left(y_{i}\right)=\frac{v\left(1-\mu\left(y_{i}\right)\right)}{\mu\left(y_{i}\right)} 0.5 k \rho^{2}\left(y_{i}\right) J\left(y_{i}\right)
$$

Recall that $\lambda\left(y_{i}\right)=\lambda\left(\mu\left(y_{i}\right), a\left(y_{i}\right)\right)$. If the elasticity condition in proposition 1 is satisfied than 
more productive employees are more intensively approached by firms. So the probability of finding a job through professional contacts is increasing in the productivity. In addition, since the unemployment rate is decreasing in $y_{i}$, the probability that a randomly chosen employee is of type $y_{i}$ is increasing in the productivity. Both of these factors imply that the probability of finding a job by recommendation is an increasing function of $y_{i}$, that is $\partial \lambda\left(y_{i}\right) / \partial y_{i}>0$ if $\partial a\left(y_{i}\right) / \partial y_{i}>0$.

The primary purpose of this paper is to analyze which groups of workers are more likely to use family and professional contacts in the process of job search. To address this question we define the following new variables $d_{0}\left(y_{i}\right)$ and $d\left(y_{i}\right)$. The former variable is an average proportion of workers with productivity $y_{i}$ using family contacts in order to find a job. In contrast, the latter variable is an average proportion of workers using professional contacts. This means:

$$
d_{0}\left(y_{i}\right)=\frac{\lambda_{0}}{\lambda_{0}+\phi\left(y_{i}\right)+\lambda\left(y_{i}\right)} \quad d\left(y_{i}\right)=\frac{\lambda\left(y_{i}\right)}{\lambda_{0}+\phi\left(y_{i}\right)+\lambda\left(y_{i}\right)}
$$

The last possibility to find a job in the model is the formal channel of job search, so the average proportion of type $y_{i}$ workers finding jobs by means of this channel can be found as $1-d_{0}\left(y_{i}\right)-d\left(y_{i}\right)$. Which worker group is relying most on family contacts? To answer this question observe that (for $r \rightarrow 0$ ):

$$
d_{0}\left(y_{i}\right)=\frac{\lambda_{0}}{\lambda_{0}+\phi\left(y_{i}\right)+\lambda\left(y_{i}\right)}=\frac{\lambda_{0}}{\sqrt{\left(\delta+\lambda_{0}+\lambda\left(y_{i}\right)\right)^{2}+\alpha\left(y_{i}-b\right) c v}-\delta}
$$

Therefore, $d_{0}\left(y_{i}\right)$ is decreasing in $y_{i}$ if the elasticity condition (10) is satisfied. On the one hand, more productive workers anticipate a larger present value of wages and exert more effort when preparing applications and, on the other hand, firms are searching more intensively for more productive applicants. Both of these factors imply that the proportion of workers finding jobs through family contacts is a decreasing function of $y_{i}$. In addition, observe that $d_{0}(b)=1$ (since $\lambda(b)=0$ and $\phi(b)=0$ ) which means that least productive workers rely exclusively on family contacts. Finally, it is not possible to predict in general whether variable $d\left(y_{i}\right)$ is increasing or decreasing in $y_{i}$. We investigate this relationship numerically in section 4 . In addition, our numerical example shows that all theoretical results also hold for $r \neq 0$.

\subsection{Wage distribution and the free-entry condition}

The second purpose of our paper is to analyze the effect of referrals on wages. As mentioned in the earlier part of our paper the equilibrium wage distribution is given by $g_{i}=e_{i} / e$ and shows the relative proportion of $y_{i}$-workers in the pool of employees. So the average wage in the economy can be found as $\bar{w}=\sum g_{i} w_{i}$. Next we find average wages conditional on the specific channel of search. To do so let $\bar{w}^{o}, \bar{w}^{s}$ and $\bar{w}^{n}$ be the corresponding average wages conditional on the search method being the family, the formal application or the network of professional contacts. In addition, let $h_{i}^{o}, h_{i}^{s}$ and $h_{i}^{n}, \forall i=1 . . p$, be the respective wage distributions so that $\sum h_{i}^{o}=1, \sum h_{i}^{s}=1$ and $\sum h_{i}^{n}=1$. For example, $h_{i}^{s}$ is the equilibrium distribution of wages among employed workers who found a job by using the formal method of search. Each of these 
three distributions can be obtained as:

$$
h_{i}^{o}=\frac{g_{i} d_{0}\left(y_{i}\right)}{\sum g_{i} d_{0}\left(y_{i}\right)} \quad h_{i}^{s}=\frac{g_{i}\left(1-d_{0}\left(y_{i}\right)-d\left(y_{i}\right)\right)}{1-\sum g_{i}\left(d_{0}\left(y_{i}\right)+d\left(y_{i}\right)\right)} \quad h_{i}^{n}=\frac{g_{i} d\left(y_{i}\right)}{\sum g_{i} d\left(y_{i}\right)} \quad \forall i=1 . . p
$$

Variable $\sum g_{i} d_{0}\left(y_{i}\right)$ is the proportion of employees who found a job with a help of a family member. It is also the total measure of these workers since the total population size is normalized to 1. In a similar way, $\sum g_{i} d\left(y_{i}\right)$ is the fraction of employees who found a job with a help of a professional contact. And the remaining part $1-\sum g_{i}\left(d_{0}\left(y_{i}\right)+d\left(y_{i}\right)\right)$ is the proportion of workers who found a job through the formal method of search. Therefore, the three average wages for each of the search channels can be found as:

$$
\bar{w}^{o}=\sum w_{i} h_{i}^{o} \quad \bar{w}^{s}=\sum w_{i} h_{i}^{s} \quad \bar{w}^{n}=\sum w_{i} h_{i}^{n}
$$

These equations allow us to compare the average wages $\bar{w}^{o}, \bar{w}^{s}$ and $\bar{w}^{n}$ and to predict whether family and/or professional referrals are associated with a wage premium or a wage penalty relative to the formal method. Either of these results will depend on the self-selection of workers into the specific channels of search. For example, we expect that family contacts will be associated with a wage penalty as this search channel is the most prevalent among the groups of workers with low wages. Formally, one can show that family contacts are associated with a wage penalty if the distribution $h_{i}^{s}$ first order stochastically dominates the distribution $h_{i}^{o}$ :

$$
\begin{gathered}
\bar{w}^{o}=\sum_{i=1}^{p} w_{i} h_{i}^{o}=w_{1}+\sum_{i=1}^{p-1} \Delta w_{i}\left(1-H_{i}^{o}\right) \quad \text { and } \quad \bar{w}^{s}=\sum_{i=1}^{p} w_{i} h_{i}^{s}=w_{1}+\sum_{i=1}^{p-1} \Delta w_{i}\left(1-H_{i}^{s}\right) \\
\text { so that } \bar{w}^{o}<\bar{w}^{s} \quad \text { if } \quad H_{i}^{s} \leq H_{i}^{o}, \forall i=1 . . p
\end{gathered}
$$

where $\Delta w_{i}=w_{i+1}-w_{i}>0$ since the wage is an increasing function of the productivity, and variables $H_{i}^{o}, H_{i}^{s}$ are the cumulative density functions so that $H_{i}^{o}=\sum_{j=1}^{i} h_{j}^{o}$ and $H_{i}^{s}=$ $\sum_{j=1}^{i} h_{j}^{s}$. The proof is presented in appendix V. In a similar way, define $H_{i}^{n}=\sum_{j=1}^{i} h_{j}^{n}$ to be the cumulative density function of wages obtained with a help of professional contacts. This channel of search is then associated with a wage premium relative to the formal method, i.e $\bar{w}^{s}<\bar{w}^{n}$, if the distribution $h_{i}^{n}$ first order stochastically dominates the distribution $h_{i}^{s}$, which is equivalent to $H_{i}^{n} \leq H_{i}^{s}, \forall i=1$..p. Intuitively, this condition holds when firms rely on professional recommendations to match with high ability workers, which is the case in our model.

Finally, the last component of the model is the Bellman equation for an open vacancy with a present value denoted by $V$. Same as workers firms are simultaneously using each of the three search channels to fill an open vacancy. At rate $\lambda_{0} u_{i} / v$ the firm is matched with an unemployed worker of type $y_{i}$ as a consequence of a family referral and at rate $\phi\left(s_{i}\right) u_{i} / v=s_{i} u_{i}$ the firm is matched with a similar worker by means of a formal application. Note that a higher measure of unemployed workers with the productivity $y_{i}$ and a more intensive job search $s_{i}$ increase the probability of filling a vacancy with this type of worker. In addition, firms may contact one of the incumbent employees to ask for the referral. An applicant of type $y_{i}$ is hired through this channel with a job-filling rate $a_{i} u_{i} \rho_{i}$, where we use notation $\rho_{i}=\rho\left(y_{i}\right)=\left[1-\left(1-\mu\left(y_{i}\right)\right)^{n}\right]$. This latter term is the probability that the contacted employee will recommend an applicant for the 
open position. Thus, the value of an open vacancy is given by:

$$
r V=-z+\frac{\lambda_{0}}{v} \sum u_{i}\left(J_{i}-V\right)+\sum s_{i} u_{i}\left(J_{i}-V\right)+\sum e_{i}\left(a_{i} \rho_{i}\left(J\left(y_{i}\right)-V\right)-a_{i}^{2} / k\right)
$$

where $z$ is the flow cost of filling a vacancy which is independent of a specific search channel. The free-entry condition of firms implies that $V=0$ in the steady-state equilibrium. Substituting the present value of profits $J_{i}$ and the optimal advertising intensity $a_{i}$ gives us the equilibrium number of vacancies:

$$
v=\lambda_{0} \frac{1-\alpha}{r+\delta} \sum u_{i}\left(y_{i}-b\right)\left[z-\frac{1-\alpha}{r+\delta} \sum s_{i} u_{i}\left(y_{i}-b\right)-0.25 k \frac{(1-\alpha)^{2}}{(r+\delta)^{2}} \sum e_{i} \rho_{i}^{2}\left(y_{i}-b\right)^{2}\right]^{-1}
$$

This is the last equilibrium equation. So the equilibrium can be defined in the following way:

Definition 1. Search equilibrium is a vector of variables $\left(U_{i}, W_{i}, J_{i}, w_{i}, s_{i}, a_{i}, \mu_{i}\right), \forall i=1 . . p$ as well as the number of vacancies $v$ and the present value of an open vacancy $V$, satisfying the asset value equations for workers (1) and (3), for firms (5) and (12), the wage equations $w_{i}=\alpha y_{i}+(1-\alpha) b$, the optimal effort equations (4) and (9), the stationary unemployment conditions (7) and the free-entry condition $V=0$.

In the next section we continue analyzing the model in a standard numerical example.

\section{Numerical example}

\subsection{Search effort and the equilibrium unemployment curve}

This section parameterizes the model to match the average labour market indicators in the OECD countries. We choose a unit period of time to be six months and set $r=0.01$ which corresponds to the annual discount rate of $2 \%$. Further, we follow Shimer (2005) and set the unemployment benefit $b$ equal to 0.4 . Fontaine (2008) uses the value of 0.15 for the U.S. economy and 0.4 for the French economy. Gautier (2002) and Cahuc and Fontaine (2009) set $b$ equal to 0.2. At the same time, Hall and Milgrom (2008) obtain a larger value of 0.71. Therefore, our choice of $b$ is in the middle range of the typical values in the literature.

Given $b=0.4$, the range of productivities in the model becomes [0.4..1]. Since education is one of the main components of the productivity, in the following we will interpret the least productive group of workers (with $y_{1}=0.4$ ) as those who have completed compulsory education. At the same time the most productive group of workers with $y_{25}=1$ will be interpreted as those who have already completed a doctoral degree. The education difference between these two groups is equal to 12 years, including 4 years in the high school, 5 years in the college/university and 3 years for obtaining a doctoral degree. Given that in the model one period of time is equal to one semester, this gives us $2 \cdot 12+1$ educational groups, so we set $p=25$. The productivity gap between the two consequent worker groups is then equal to $0.025^{3}$.

\footnotetext{
${ }^{3}$ The choice of $p$ is not essential for the model since neither of the group-specific variables depends on the total number of productivity groups. Nevertheless, with a large value of $p$ the model can serve as an approximation of the market with a continuous productivity distribution and allows an intuitive interpretation of worker groups as those with different levels of educational attainment.
} 
Next, we take the value of the separation rate $\delta=0.15$ which corresponds to the average job duration of $1 /(2 \cdot 0.15)=3.3$ years. Pissarides (2009) and Shimer (2005) choose the value of $\delta$ equal to 0.1 with one unit of time being a quarter. This corresponds to the average job duration of $1 /(4 \cdot 0.1)=2.5$ years. Hall and Milgrom (2008) choose the value of $3 \%$ per month, so the average job duration in their model is $1 /(12 \cdot 0.03)=2.78$ years. Hobijn und Sahin (2009), however, when estimating the montly job separation rate for OECD countries for the period $1968-2004$ report to be at most $2.3 \%$ (Spain). So the average job duration is $1 /(12 * 0.023)=3.6$ years. Therefore, our estimate falls within the standard bounds.

The job-finding rate through the channel of family contacts $\lambda_{0}$ is chosen to be 0.3 and is defined by the unemployment rate of the least productive workers being equal to $\mu(b)=\delta /(\delta+$ $\left.\lambda_{0}\right)=0.33$. Note that the productivity of these workers is equal to the unemployment benefit and so the gain from finding a job is zero, which means that sending formal job applications is too costly for this group of workers. At the same time, $w(b)=b$ so firms obtain zero profits from hiring the least productive workers. Therefore, it is not profitable for firms to direct their search towards these employees. Hence, the only way for the unproductive workers to find a job is to rely on family contacts. For this reason the average unemployment duration of this group of workers is equal to 1.6 years and is the largest in the population.

We choose the number of workers' professional contacts equal to 50 as in Cahuc and Fontaine (2009), while Fontaine (2008) uses $n=40$ in a benchmark model of his paper. These numbers are in line with the empirical evidence, for example, in their recent study Cingano and Rosolia (2012) find that the median number of professional contacts in Italy is equal to 32 . This number is higher in Germany and is equal to 43 according to Glitz (2013). The workers' bargaining power $\alpha$ is set equal to 0.72 as in Shimer (2005). This means that the maximum wage in the economy is equal to $0.72 \cdot 1+(1-0.72) \cdot 0.4=0.832$. With this parameter choice we can calculate the annual return to schooling which is implied by the model: $\ln (0.83 / 0.4) / 12=0.061$, so the average salary increase for an additional year of education is equal to $6.1 \%$. This value is in line with the parameters presented in Card (2001).

An important feature of our model is its invariance to the shape of the productivity distribution and the number of vacancies. Recall that the two key variables in the model $d_{0}\left(y_{i}\right)$ and $d\left(y_{i}\right)$ correspond to the relative fractions of workers finding jobs with a help of family and professional contacts. Thus these variables are defined in relative terms and are independent of the productivity distribution $f_{i}$. Moreover, the total number of vacancies only enters in the two multiplicative terms $k v$ and $c v$, where $k$ and $c$ are the unobservable parameters of the two cost functions. To identify variables $k v$ and $c v$, first, we define a median productivity group. According to the OECD report 2013 (table A1.1a), 47\% of workers aged 25-64 in the US report the high school diploma to be the maximum educational achievement. Further, there is a small proportion of workers equal to $11 \%$ who did not complete their high school studies. Therefore, we can conclude that $58 \%$ of workers in the US have at most a high school diploma. In the model this corresponds to the productivity level $y_{8}=0.575$ ( 8 semesters of schooling). So a median worker in the US has the level of schooling just below the high school. Based on this information we conjecture that a median worker in our model should have the productivity $y_{7}=0.55$.

In the second step, having defined a median worker group, we simultaneously choose variables $k v$ and $c v$ to target $d_{0}\left(y_{7}\right)+d\left(y_{7}\right)=0.4$ and $\mu\left(y_{7}\right)=0.087$. The first of these conditions implies 
that $40 \%$ of workers in the median group find employment by means of referrals. This assumption is in line with the empirical observation that $30 \%$ to $60 \%$ of the employees in developed countries rely on social contacts in order to find a job (see Ioannides and Datcher Loury (2004) for an overview). The second condition implies that the unemployment rate in the median group of workers is equal to $8.7 \%$. This number is the average unemployment rate in the United States in the recent years (BLS, 2009-2013). Our calibration strategy yields $k v=0.24$ and $c v=22.07$. Table 1 presents our calibration for the benchmark case.

\begin{tabular}{c|c|l} 
Variable & Value & Explanation, source and target \\
\hline$n$ & 50 & Network size (Cahuc and Fontaine (2009)) \\
$r$ & 0.01 & Annual interest rate of 2\% \\
$\lambda_{0}$ & 0.3 & Unemployment of the least able worker $=33 \%$ \\
$\delta$ & 0.15 & Average job duration of 3.3 years \\
$\alpha$ & 0.72 & Worker's bargaining power (Shimer (2005)) \\
$b$ & 0.4 & Unemployment benefit (Shimer (2005)) \\
$p$ & 25 & Number of productivity types \\
$c v$ & 22.07 & Unemployment of the median worker $=8.7 \%$ \\
$k v$ & 0.24 & Referral hiring of the median worker=40\% \\
\hline
\end{tabular}

Table 1: Values of the model parameters

Next we describe our results. Figure 3 (left panel) presents variables $d_{0}\left(y_{i}\right), 1-d_{0}\left(y_{i}\right)-d\left(y_{i}\right)$ and $d\left(y_{i}\right)$ for every worker group $i=1 . .25$. These are the average proportions of workers finding employment by means of family contacts, formal applications and professional contacts respectively. As we proved in the theoretical part of the paper the average fraction of workers using family contacts to find a job, $d_{0}\left(y_{i}\right)$, is a decreasing curve and the lowest productivity group never finds jobs through channels other than family contacts. Therefore, the reliance on family contacts falls down from $100 \%$ for the least able workers to only $7 \%$ for the most productive group. Intuitively, even though family contacts become less important for more productive workers, our model does not exclude situations when talented employees are recommended and work for the same employer as their parents.

Now consider professional relations. Figure 4 (the right panel) shows that firms exert more advertising effort $a\left(y_{i}\right)$ when targeting the more productive group of incumbent employees. This means that the elasticity condition in proposition 1 is satisfied and the positive effect of higher profits is dominating for firms. This in turn implies that the job finding rate $\lambda\left(y_{i}\right)$ is an increasing function of productivity. On the one hand, even if firms contacted their incumbent employees in a random and undirected manner they would be more likely to be in contact with a more productive worker as the equilibrium unemployment rate is decreasing with $y_{i}$ (see the right panel of figure 4). On the other hand, it is profitable for firms to direct their search towards the more productive group of incumbent employees in the expectation of a good applicant. Therefore, both effects are reinforcing and amplifying each other and the network job-finding rate $\lambda\left(y_{i}\right)$ is an increasing and a convex function of $y_{i}$ (see the left panel of figure 4). Thus the average proportion of workers using professional contacts to find a job, $d\left(y_{i}\right)$ is increasing from $0 \%$ for the least productive group up to $60 \%$ for the most productive group. Moreover, the network of professional contacts is a dominating channel of search for workers with a productivity above $y_{15}=0.75$. 

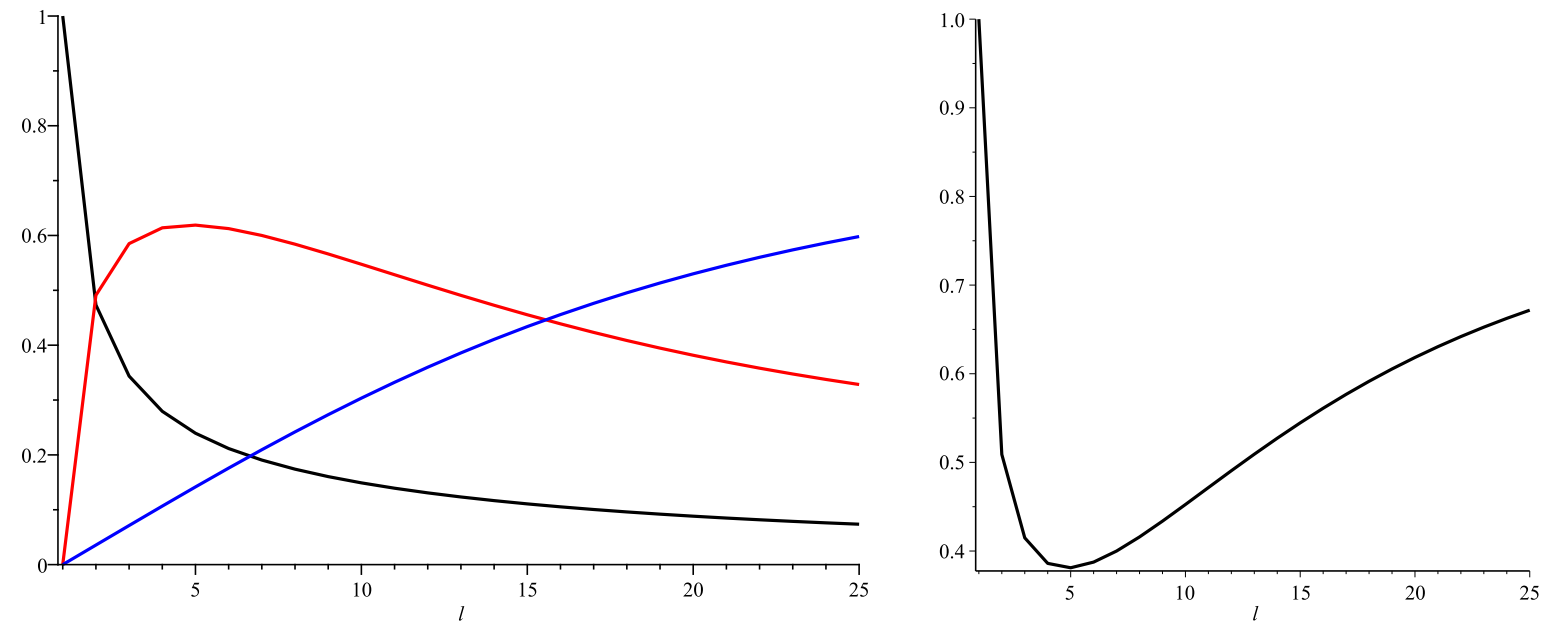

Figure 3: Left panel: The graph for average proportions of workers using family (black), professional (blue) contacts and the formal application (red) in the job search process for different productivity levels. Right panel: The graph for the average proportions of workers using social contacts in the job search for different productivity levels (U-shape).

Finally, consider the formal applications channel. Figure 3 (left panel) shows that the relative fraction of workers finding jobs through this channel, $1-d_{0}\left(y_{i}\right)-d\left(y_{i}\right)$ is increasing for productivities below $y_{5}=0.5$ and decreasing thereafter. Intuitively, for the less able workers the probability of being referred for a job $\lambda\left(y_{i}\right)$ is still relatively low, but the wage $w_{i}$ is already sufficiently large to motivate these workers for preparing formal applications. However, as the productivity is increasing, workers' chances of being referred for a job are improving and the incentives to invest costly effort and time in preparing applications are mitigated. In line with this reasoning figure 4 (left panel) shows that the search effort $s\left(w_{i}, \lambda_{i}\right)$ is an increasing but a concave function of $y_{i}$ as the positive effect of a higher wage is partially neutralized by the negative effect of a higher $\lambda_{i}$. In addition, figure 3 (left panel) illustrates that the formal channel of search is dominating for workers in the middle range of productivities between $y_{2}=0.425$ and $y_{15}=0.75$ reaching a maximum of $62 \%$ for workers with a productivity $y_{5}=0.5$.

To sum up, our model is able to jointly replicate a number of empirical observations. First, without separating social contacts into different types the model shows that the reliance on social contacts $d_{0}\left(y_{i}\right)+d\left(y_{i}\right)$ has a distinct U-shape pattern falling down from $100 \%$ to $38 \%$ for workers with $y_{5}=0.5$ and rising again to the level of $67 \%$ for the most productive workers (see figure 3 (right panel)). Second, when the two types of contacts are separated, then family contacts are more likely to have a negative effect on wages since family referrals are strongly biased towards the left tail of the productivity distribution. In contrast, professional contacts are more likely to have a positive effect on wages since these contacts are biased towards the right tail of the distribution. However, the overall effect of referrals on wages is ambiguous and depends on the exact proportions of high and low types in the population. Therefore, we continue the analysis of wages by considering an explicit shape of the productivity distribution $f_{i}$. 

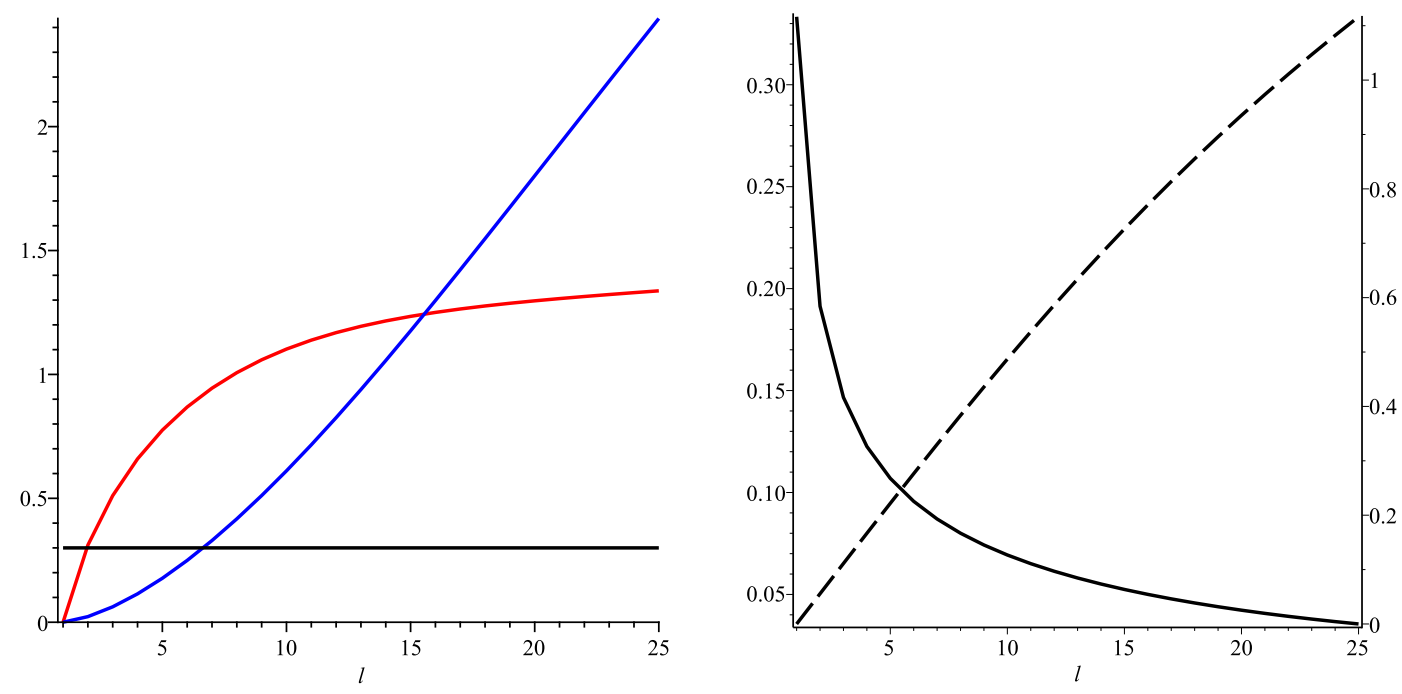

Figure 4: Left panel: The graphs for $\lambda_{0}$ (black), $\phi\left(s\left(y_{i}\right)\right)$ (red) and for $\lambda\left(y_{i}\right)$ (blue) for different productivity levels. Right panel: The optimal advertising rate $a\left(y_{i}\right)$ by firms (dashed) and the graph for the unemployment rate $\mu\left(y_{i}\right)$ (solid) for different productivity levels.

\subsection{Wage and productivity distributions}

It is a well documented empirical fact (see Neal and Rosen (2000) and Mortensen (2003)) that a typical earnings distribution is hump-shaped and positively skewed with a mean value larger than the median. Therefore, it is often well approximated by the log-normal distribution. In our model the distribution $f_{i}$ is discrete, so we use the Negative Binomial productivity distribution which is a discrete counterpart of the log-normal distribution. In particular, we rely on a special case of the density which is known as the Polya distribution. Given that this distribution has an infinite range we truncate it at $i=25$. The productivity density $f_{i}$ is then characterized by two parameters $t$ and $\pi$ and takes the form:

$f_{i}=\frac{\tilde{f}_{i}}{\sum_{i=1}^{25} \tilde{f}_{i}} \quad$ where $\quad \tilde{f}_{i}=\left(\begin{array}{c}i+t-2 \\ i-1\end{array}\right)(1-\pi)^{t} \pi^{i-1}=\frac{\Gamma(i+t-1)}{(i-1) ! \Gamma(t)}(1-\pi)^{t} \pi^{i-1}, \quad i=1,2, \ldots$

Negative Binomial a discrete probability distribution of the number of successes in a sequence of independent and identically distributed Bernoulli trials before a specified number of failures occurs. Here $t$ is the specified number of failures and $\pi$ is the probability of success. However, in the specific case of Polya distribution $t$ is a real-valued parameter rather than an integer, which allows a more accurate approximation of the data. To identify parameters $t$ and $\pi$ we exploit the definition of the median worker having the productivity $y_{7}=0.55$ and the fact that $58 \%$ of workers in the U.S. have at most a high school degree (corresponding to $y_{8}=0.575$ ), mentioned above. Therefore, we set $\sum_{i=1}^{7} f_{i}=0.5$ and $\sum_{i=1}^{8} f_{i}=0.58$.

Next, we consider the free-entry condition. To identify the cost of an open vacancy $z$ we set the market tightness $v / u$ equal to 1 , where $u=\sum_{i=1}^{p} \mu_{i} f_{i}$ is the equilibrium unemployment rate in the economy. This value coincides with the calibration of Shimer (2005) but it is larger than 0.72 chosen by Pissarides (2009) and derived from the Job Openings and Labor Turnover Survey (JOLTS). To defend our choice we argue that some vacancies are not captured by JOLTS, for example, some positions are filled without ever reporting a vacancy. In particular, these 
positions are very likely to be filled through social networks and, therefore, we consider the market tightness equal to 1 an appropriate choice for our model. The last set of parameters is presented in table 2 :

\begin{tabular}{c|c|l} 
Variable & Value & Explanation, source and target \\
\hline$t$ & 2.98 & $58 \%$ have at most a high school degree $\left(y_{8}=0.575\right)($ OECD $(2013))$ \\
$\pi$ & 0.717 & Productivity of a median worker $y_{7}=0.55$ \\
$z$ & 0.390 & Market tightness equal to 1 (Shimer $(2005))$ \\
\hline
\end{tabular}

Table 2: Values of the model parameters

We get $z=0.39$ (flow cost of an open vacancy) in equilibrium, which is close to the value of 0.4 chosen for the formal search method by Cahuc and Fontaine (2009). Shimer (2005) has chosen the value of 0.213 for this parameter, while Fontaine (2008) uses the number 0.3. The choice of Pissarides (2009) is closer to our value, in his calibration the cost of an open vacancy is equal to 0.36. Another influential calibration is due to Hagedorn and Manovskii (2008). These authors find that the capital cost of an open vacancy is equal to 0.47 and the personnel cost is 0.11 , which gives a value 0.58 . Hence, $z=0.39$ is in the middle range of standard values.

The productivity density function $f_{i}$ with $t=2.98$ and $\pi=0.717$ is illustrated by the solid curve on figure 5 (left panel). The equilibrium wage distribution $g_{i}$, defined in the theoretical part of the paper, is shown by the dashed curve on the same figure. The corresponding CDFs are shown on figure 5 (right panel). The wage distribution $g_{i}$ first order stochastically dominates the productivity distribution $f_{i}$. This is because the unemployment rate is higher than the average among the less productive types and lower among the more productive. Both distributions are, however, very close to each other.
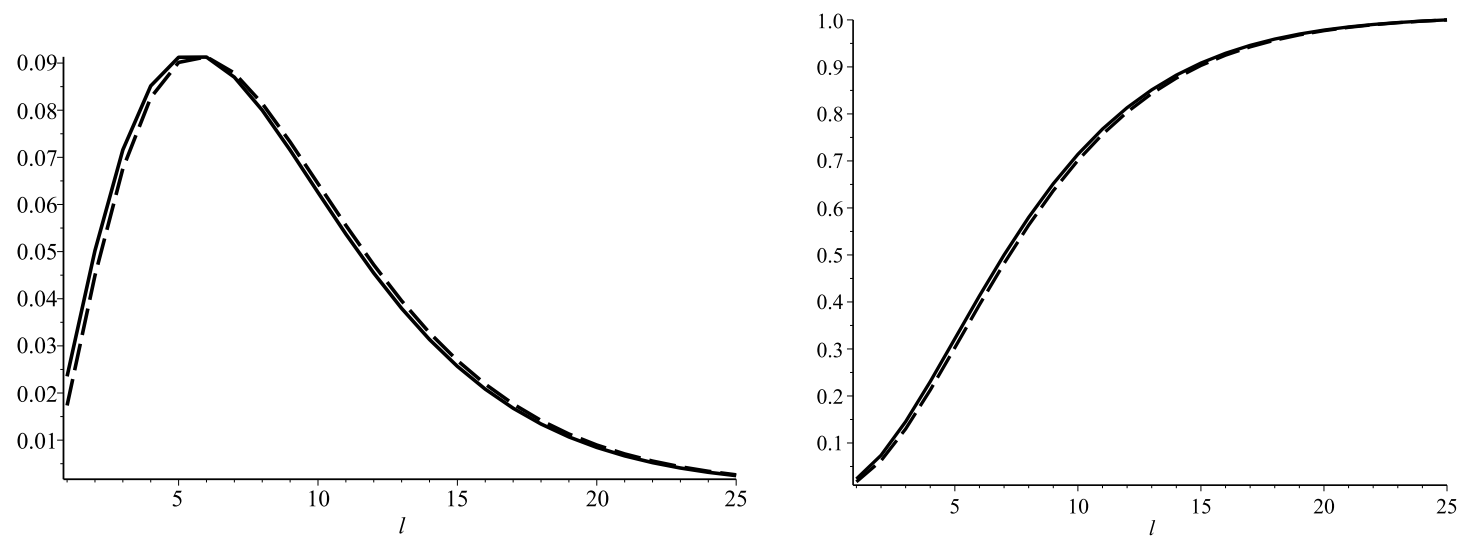

Figure 5: Left panel: The graphs for the probability mass functions of the Negative Binomial distribution (solid) and of the equilibrium wage distribution (dashed). Right panel: The graphs for the CDFs of the Negative Binomial distribution (solid) and of the equilibrium wage distribution (dashed).

The equilibrium wage/productivity distributions conditional on the job search channel $h_{i}^{o}$ (black), $h_{i}^{s}$ (red) and $h_{i}^{n}$ (blue), as well as their corresponding CDFs are presented on figure 6. The wage distribution of workers finding jobs through their families, $h_{i}^{o}$, is first order stochastically dominated by the wage distribution of employees who used a formal application, $h_{i}^{s}$. The probability mass of the distribution $h_{i}^{o}$ is mostly concentrated in the lower productivity 
range and so most of the employees in this group are the low productivity types with low wages. The average productivity of workers using the family channel is equal to 0.536 and the average wage is $\bar{w}^{o}=0.498$. In contrast, the average productivity of workers using the formal channel is equal to 0.580 and the average wage is $\bar{w}^{s}=0.530$. Therefore, we conclude that the family search channel is associated with a wage penalty of $6 \%$ compared to the formal channel.
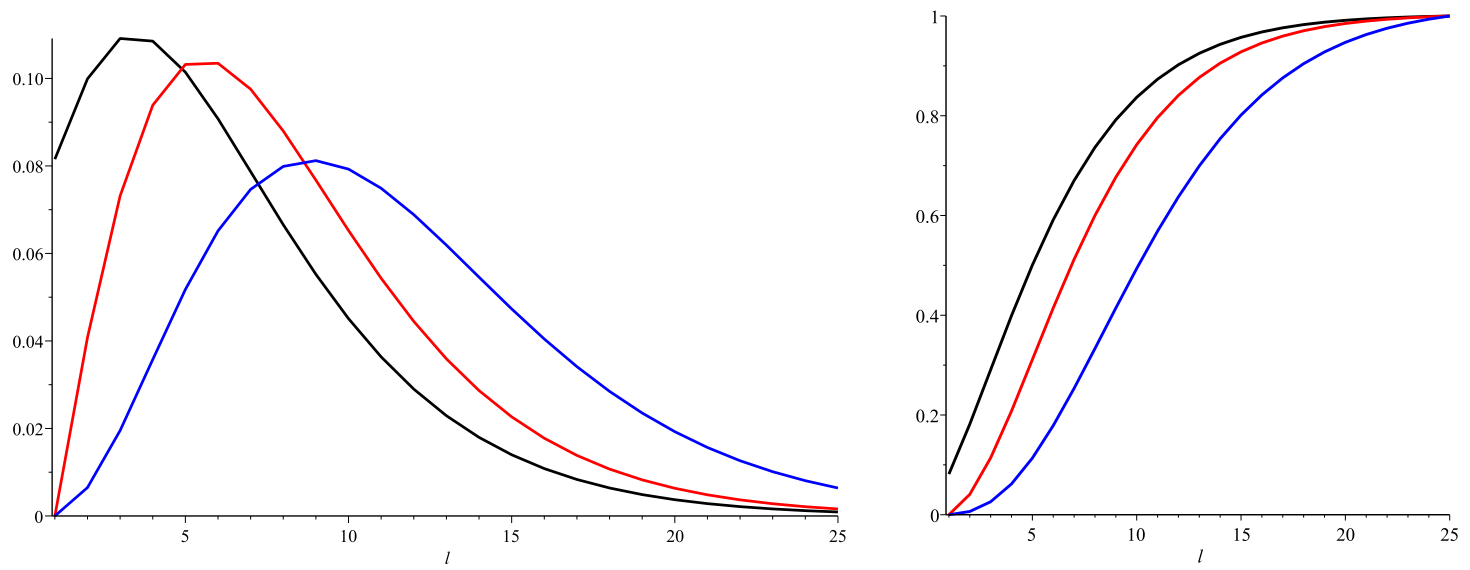

Figure 6: Left panel: The graphs for wage distribution functions $h_{i}^{o}$ (black), $h_{i}^{s}$ (red) and for $h_{i}^{n}$ (blue) corresponding to different channels of job search. Right panel: The graphs for cumulative wage distribution functions $H_{i}^{0}$ (black), $H_{i}^{s}$ (red) and for $H_{i}^{n}$ (blue)

The second distribution, $h_{i}^{s}$, is in turn first order stochastically dominated by the wage distribution of workers who used professional contacts, $h_{i}^{n}$. Here the average productivity is equal to 0.656 and the average wage is $\bar{w}^{n}=0.584$ (see table 3 ). The probability mass of the distribution $h_{i}^{n}$ is shifted to the right and so this density is mostly concentrated in the middle range of the productivities. This is due to the fact that the proportion of high productivity workers in the population is relatively low and almost all of them are employed. Finally, observe that finding a job with a help of professional contacts is associated with a wage premium of 10\%. Therefore, we can rank $\bar{w}^{o}<\bar{w}^{s}<\bar{w}^{n}$, which is the second prediction of the paper: when the two types of contacts are separated, then family contacts are more likely to have a negative effect on wages, whereas professional contacts are more likely to have a positive effect. Capellari and Tatsiramos (2013) confirm this result with their empirical finding for the UK that highskilled individuals, whose employed friends are non-relatives, earn higher wages and low-skilled individuals, whose employed friends are relatives, experience a wage penalty. Sylos Labini (2004) confirm this finding for Italy.

\begin{tabular}{l|c|c|c|c} 
& \multicolumn{3}{|c|}{ Specific search channel } & \\
\hline Variable & Family & Formal & Professional & All channels \\
\hline Average productivity & 0.536 & 0.580 & 0.656 & 0.590 \\
Average wage & 0.498 & 0.530 & 0.584 & 0.536 \\
Proportion of employees & 0.213 & 0.541 & 0.247 & 1 \\
\hline
\end{tabular}

Table 3: Model-generated statistics for the benchmark calibration

Based on table 3 we can also calculate the average wage of employees who found a job by 
means of referrals, i.e. both types of social contacts. Let this variable be denoted by $\bar{w}^{c}$ :

$$
\bar{w}^{c}=\frac{\bar{w}^{o} \sum g_{i} d_{0}\left(y_{i}\right)+\bar{w}^{n} \sum g_{i} d\left(y_{i}\right)}{\sum g_{i} d_{0}\left(y_{i}\right)+\sum g_{i} d\left(y_{i}\right)}=\frac{0.498 \cdot 0.213+0.584 \cdot 0.247}{0.213+0.247}=0.544
$$

$\bar{w}^{c}=0.544$ is higher than $\bar{w}^{s}=0.530$. Thus, in the benchmark case the positive effect of professional networks is dominating the negative effect of family contacts and job referrals are associated with a wage premium of $2.6 \%$. However, this result is sensitive to the relative proportions of workers relying on family and professional relations. To elaborate on this point we perform comparative statics analysis with respect to parameter $t$ which is a shift parameter of the distribution. Intuitively, a lower value of $t$ corresponds to labour markets with a larger proportion of low skilled workers. In the first step, we find $t^{*}$ for the neutral scenario when the effect of referrals on wages is zero. Other parameters remain unchanged. We get the value $t^{*}=2.21$. Our results for the neutral scenario are presented in table 4 . In the second step, we recognize that the effect of referrals should be negative for $t<t^{*}$. Therefore, we consider a wage penalty scenario as a symmetric case around $t^{*}: t=1.45=2.21-(2.98-2.21)$, substracting from $t^{*}$ the difference between the benchmark value of $t=2.98$ and $t^{*}$. Our results for the wage penalty scenario $(t=1.45)$ are presented in table 5 :

\begin{tabular}{l|c|c|c|c} 
& \multicolumn{3}{|c|}{ Specific search channel } & \\
\hline Variable & Family & Formal & Professional & All channels \\
\hline Average productivity & 0.493 & 0.545 & 0.617 & 0.545 \\
Average wage & 0.467 & 0.504 & 0.556 & 0.504 \\
Proportion of employees & 0.270 & 0.538 & 0.193 & 1 \\
\hline
\end{tabular}

Table 4: Model-generated statistics with $t=2.21$

\begin{tabular}{l|c|c|c|c} 
& \multicolumn{3}{|c|}{ Specific search channel } & \\
\hline Variable & Family & Formal & Professional & All channels \\
\hline Average productivity & 0.454 & 0.511 & 0.575 & 0.498 \\
Average wage & 0.439 & 0.480 & 0.526 & 0.471 \\
Proportion of employees & 0.371 & 0.496 & 0.134 & 1 \\
\hline
\end{tabular}

Table 5: Model-generated statistics with $t=1.45$

The productivity density function $f_{i}$ and the equilibrium wage distribution $g_{i}$ for the neutral scenario $(t=2.21)$ are illustrated by the solid and dashed curves on figure 7 (left panel). $f_{i}$ in this case is close to our benchmark productivity distribution, although shifted to the left. Compared to the benchmark scenario, more workers are relying on their families in the job search process $(0.270>0.231)$ and less workers find jobs by means of professional contacts $(0.193<0.247)$. From table 4 we also see that family contacts have a negative effect of wages, whereas professional contacts are associated with a wage premium: $\bar{w}^{o}=0.467<\bar{w}^{s}=0.504<\bar{w}^{n}=0.556$. Therefore, we conclude that these results are due to the self-selection of workers into channels and are robust to different specifications of the productivity distribution. The average referral wage for this case can be calculated from table 4 :

$$
\bar{w}^{c}=\frac{0.467 \cdot 0.270+0.556 \cdot 0.193}{0.270+0.193}=0.504
$$


This value is equal to $\bar{w}^{s}$ and so the average effect of referrals on wages is equal to zero.
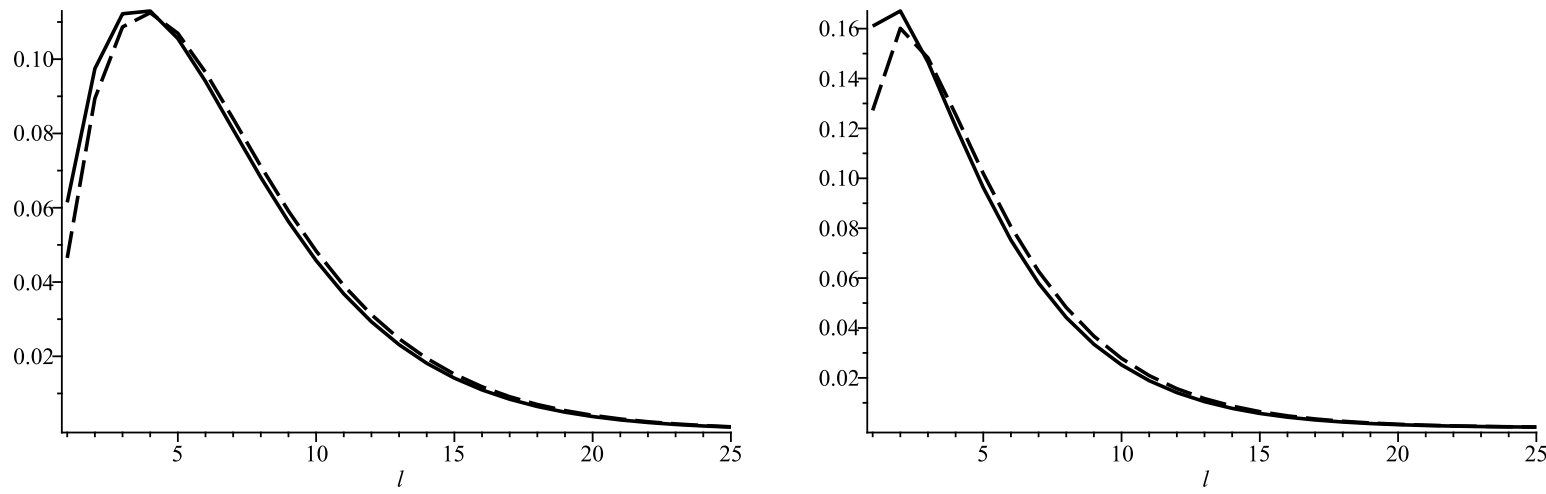

Figure 7: Left panel: The graphs for the probability mass functions of the Negative Binomial distribution (solid) and the equilibrium wage distribution (dashed) for $t=2.21$. Right panel: The graphs for the probability mass functions of the Negative Binomial distribution (solid) and the equilibrium wage distribution (dashed) for $t=1.45$.

The productivity density function $f_{i}$ and the equilibrium wage distribution $g_{i}$ for the wage penalty scenario $(t=1.45)$ are illustrated by the solid and dashed curves on the right panel of figure 7. This scenario is associated with a further increase in the proportion of workers relying on families $(0.371>0.270)$ and a lower importance of professional contacts $(0.134<0.193)$. As before, table 5 confirms that family contacts are associated with a wage penalty, whereas professional networks with wage premium, since $\bar{w}^{o}=0.439<\bar{w}^{s}=0.480<\bar{w}^{n}=0.526$. The average referral wage can be calculated from table 5 :

$$
\bar{w}^{c}=\frac{0.439 \cdot 0.371+0.526 \cdot 0.134}{0.371+0.134}=0.462
$$

This value is lower than $0.480=\bar{w}^{s}$ and so there is a wage penalty equal to $1.9 \%$.

This section shows that the negative effect of family contacts and the positive effect of professional contacts are both robust to the exact specification of the productivity distribution in the population. However, the average effect of referrals on wages is sensitive to the specific distribution and can be positive or negative depending on the relative proportions of high and low productivity groups. Thus, our model provides and additional explanation for the ambiguous results reported in the empirical literature, which were summarized in the introduction.

\section{Conclusions}

This paper develops a labour market matching model with a finite number of heterogeneous worker groups and three channels of job search: family contacts, formal applications and professional contacts. Moreover, the model relies on the assumption of network homophily meaning that workers connected in the network are all of the same ability/productivity type. In this framework, we are able to generate a significant U-shape relationship between the frequency of referral hiring and the productivity/skill level of the worker.

Family contacts are exogenous in the model and serve as a residual method of search. Nevertheless, every worker may choose an endogenous search intensity, which can be interpreted as 
a total effort and time invested in preparing job applications. It turns out that the gain from preparing applications is increasing in the worker type and so it is relatively costly for low productivity workers to rely on the formal channel. On the other hand, firms with open vacancies direct their network search towards more productive incumbent employees in the anticipation of higher profits. Therefore, the family channel of search is predominantly employed by workers in the left tail of the productivity distribution, whereas the network of professional contacts is largely used by more productive workers. These two mechanisms explain the U-shaped referral hiring pattern. Moreover, this relationship is invariant to the exact shape of the productivity distribution, which is an indicator for the robustness of our result.

In addition, the U-shaped employment pattern implies that the effect of professional (family) contacts on wages is positive (negative) with respect to the formal channel. This result is due to the endogenous sorting of workers across the channels and is robust to the exact shape of the productivity density. However, the average effect of referrals on wages is ambiguous and depends on the relative proportions of high and low ability workers in the population. We believe these results shed some light on the contradicting empirical evidence and may serve as a further step in the explanation of the "referral puzzle", at least from a theoretical perspective.

\section{Acknowledgements}

We are thankful to Herbert Dawid as well as to participants of the Networks' seminar at IMW, Bielefeld University for useful comments and suggestions.

\section{$7 \quad$ Appendix}

\section{Appendix I. Proof of Lemma 1:}

The rent $R_{i}$ can be obtained as a solution of the following quadratic equation:

$$
0.25 c v R_{i}^{2}+\left(r+\delta+\lambda_{0}+\lambda_{i}\right) R_{i}-\left(w_{i}-b\right)=0
$$

Since workers will only accept the job with $R_{i} \geq 0$ it holds that:

$$
R_{i}=\frac{2}{c v}\left[\sqrt{\left(r+\delta+\lambda_{0}+\lambda\left(y_{i}\right)\right)^{2}+\left(w_{i}-b\right) c v}-\left(r+\delta+\lambda_{0}+\lambda_{i}\right)\right]
$$

therefore the optimal effort is given by $s_{i}=0.5 c R_{i}$, where $R_{i}$ is increasing in the wage $w_{i}$ but decreasing in $\lambda_{i}$ :

$$
\frac{\partial R_{i}}{\partial \lambda_{i}}=\frac{2}{c v}\left[\sqrt{\frac{\left(r+\delta+\lambda_{0}+\lambda_{i}\right)^{2}}{\left(r+\delta+\lambda_{0}+\lambda_{i}\right)^{2}+\left(w_{i}-b\right) c v}}-1\right]<0
$$




\section{Appendix II. Proof of Lemma 2:}

Differentiate $\lambda_{i}$ with respect to $\mu_{i}$ for a given fixed advertising intensity $a_{i}$ :

$$
\begin{aligned}
\frac{\partial \lambda\left(\mu_{i}, a_{i}\right)}{\partial \mu_{i}} & =v a_{i}\left[-\frac{1}{\mu_{i}^{2}}\left[1-\left(1-\mu_{i}\right)^{n}\right]+\frac{1-\mu_{i}}{\mu_{i}} n\left(1-\mu_{i}\right)^{n-1}\right] \\
& =\frac{v a_{i}}{\mu_{i}^{2}}\left[-1+\left(1-\mu_{i}\right)^{n}+n \mu_{i}\left(1-\mu_{i}\right)^{n}\right] \\
& =\frac{v a_{i}}{\mu_{i}^{2}}\left[\left(1-\mu_{i}\right)^{n}\left(n \mu_{i}+1\right)-1\right]
\end{aligned}
$$

Let $\sigma(\mu)$ denote the first term in the square bracket (suppressing the subindex), i.e. $\sigma(\mu)=$ $(1-\mu)^{n}(n \mu+1)$. Note that $\sigma(0)=1$ and $\sigma(1)=0$. Moreover, $\sigma(\mu)$ is a decreasing function of $\mu$ for $0<\mu<1$ :

$$
\begin{aligned}
\frac{\partial \sigma}{\partial \mu} & =-n(1-\mu)^{n-1}(n \mu+1-\mu+\mu)+(1-\mu)^{n} n \\
& =n\left[-(1-\mu)^{n}-(1-\mu)^{n-1} \mu(n+1)+(1-\mu)^{n}\right]=-n(1-\mu)^{n-1} \mu(n+1)<0
\end{aligned}
$$

This proves that $\sigma(\mu)=(1-\mu)^{n}(n \mu+1)<1$ and, therefore, $\partial \lambda\left(\mu_{i}, a_{i}\right) / \partial \mu_{i}<0$ for $0<\mu<1$. Next, applying the L'Hopital's rule one can show that:

$$
\lim _{\mu_{i} \rightarrow 0} \lambda_{i}=v a_{i} \frac{\lim _{\mu_{i} \rightarrow 0}\left(1-\left(1-\mu_{i}\right)^{n}\right)}{\lim _{\mu_{i} \rightarrow 0} \mu_{i}}=v a_{i} \lim _{\mu_{i} \rightarrow 0} n\left(1-\mu_{i}\right)^{n-1}=n v a_{i}
$$

and also $\lim _{\mu_{i} \rightarrow 1} \lambda_{i}=0$. This completes the proof of lemma 2 .

\section{Appendix III: Proof of Lemma 3}

First, note that at the intersection between the curves $\mu(\lambda, y)$ and $\lambda(\mu, a)$ (see figure), the latter curve (NC) is flatter than the former curve (UC), this means:

$$
0>\frac{\partial \lambda(\mu, a)}{\partial \mu}>\left[\frac{\partial \mu(\lambda, y)}{\partial \lambda}\right]^{-1} \quad \Rightarrow \quad 0<\frac{\partial \lambda(\mu, a)}{\partial \mu} \cdot \frac{\partial \mu(\lambda, y)}{\partial \lambda}<1
$$

Taking a total derivative of $\mu(\lambda, y)$ with respect to $y$ yields the following:

$$
d \mu=\frac{\partial \mu(\lambda, y)}{\partial \lambda} d \lambda+\frac{\partial \mu(\lambda, y)}{\partial y} d y \quad \text { and } \quad d \lambda=\frac{\partial \lambda(\mu, a)}{\partial \mu} d \mu
$$

Therefore, we get the following result:

$$
\frac{\partial m(y, a)}{\partial y}=\frac{d \mu}{d y}=\frac{\partial \mu(\lambda, y)}{\partial y}\left[1-\frac{\partial \mu(\lambda, y)}{\partial \lambda} \cdot \frac{\partial \lambda(\mu, a)}{\partial \mu}\right]^{-1}<0
$$

since $\partial \mu(\lambda, y) / \partial y<0$ and expression in the square bracket is positive. Similarly, we can show that $\partial m(y, a) / \partial a<0$.

\section{Appendix IV. Proof of Proposition 1:}

(i) First, note the following results from before:

$$
\frac{\partial m(y, a)}{\partial y}<0 \quad \frac{\partial m(y, a)}{\partial a}<0 \quad \frac{\partial a(m, y)}{\partial m}>0 \quad \frac{\partial a(m, y)}{\partial y}>0
$$


Taking a total derivative of $m(a, y)$ with respect to $y$ yields the following:

$$
\begin{gathered}
d m=\frac{\partial m(y, a)}{\partial y} d y+\frac{\partial m(y, a)}{\partial a} d a \\
=\frac{\partial m(y, a)}{\partial y} d y+\frac{\partial m(y, a)}{\partial a}\left[\frac{\partial a(m, y)}{\partial m} d m+\frac{\partial a(m, y)}{\partial y} d y\right] \\
d m \underbrace{\left[1-\frac{\partial m(y, a)}{\partial a} \frac{\partial a(m, y)}{\partial m}\right]}_{>0}=\underbrace{\left[\frac{\partial m(y, a)}{\partial y}+\frac{\partial m(y, a)}{\partial a} \frac{\partial a(m, y)}{\partial y}\right]}_{<0} d y \Rightarrow \frac{d m}{d y}<0
\end{gathered}
$$

(ii) Let $\rho\left(y_{i}\right) \equiv\left[1-\left(1-\mu\left(y_{i}\right)\right)^{n}\right]$ denote the probability of a referral, it then holds that $a\left(y_{i}\right)=$ $0.5 k \rho\left(y_{i}\right) J\left(y_{i}\right)$, where $J\left(y_{i}\right)=(1-\alpha)\left(y_{i}-b\right) /(r+\delta)$ given the free-entry condition $V=0$. Next differentiate $a\left(y_{i}\right)$ with respect to $y_{i}$ to obtain:

$$
\begin{gathered}
\frac{\partial a\left(y_{i}\right)}{\partial y_{i}}=\frac{\partial \rho\left(y_{i}\right)}{\partial y_{i}} J\left(y_{i}\right)+\rho\left(y_{i}\right) \frac{\partial J\left(y_{i}\right)}{\partial y_{i}}=\frac{\partial \rho\left(y_{i}\right)}{\partial y_{i}} \frac{(1-\alpha)\left(y_{i}-b\right)}{r+\delta}+\rho\left(y_{i}\right) \frac{(1-\alpha)}{r+\delta} \\
\text { Therefore, } \quad \frac{\partial a\left(y_{i}\right)}{\partial y_{i}}>0 \quad \text { if } \quad \frac{\partial \rho\left(y_{i}\right)}{\partial y_{i}} \cdot \frac{y_{i}-b}{\rho\left(y_{i}\right)}>-1
\end{gathered}
$$

Appendix V. Suppose the distribution $h_{i}^{s}$ first order stochastically dominates the distribution $h_{i}^{0}$, then it holds $H_{i}^{s} \leq H_{i}^{o}, \forall i=1 . . p$. The average wage $\bar{w}^{o}$ can be written as:

$$
\begin{aligned}
\bar{w}^{o} & =\sum_{i=1}^{p} w_{i} h_{i}^{o}=w_{1} h_{1}^{o}+w_{2} h_{2}^{o}+w_{3} h_{3}^{o}+\ldots+w_{p-1} h_{p-1}^{o}+w_{p} h_{p}^{o} \\
& =w_{1}\left(h_{1}^{o}+h_{2}^{o}+\ldots+h_{p}^{o}\right)+\left(w_{2}-w_{1}\right)\left(h_{2}^{o}+\ldots+h_{p}^{o}\right)+\ldots+\left(w_{p}-w_{p-1}\right) h_{p}^{o} \\
& =w_{1}+\sum_{i=1}^{p-1}\left(w_{i+1}-w_{i}\right) \sum_{j=i+1}^{p} h_{j}^{o}=w_{1}+\sum_{i=1}^{p-1}\left(w_{i+1}-w_{i}\right)\left(1-\sum_{j=1}^{i} h_{j}^{o}\right) \\
& =w_{1}+\sum_{i=1}^{p-1}\left(w_{i+1}-w_{i}\right)\left(1-H_{i}^{o}\right)
\end{aligned}
$$

In a similar way, one can derive an equation for $\bar{w}^{s}$. So that $\bar{w}^{o}<\bar{w}^{s}$ if $H_{i}^{s} \leq H_{i}^{o}, \forall i=1$..p.

\section{References}

[1] Addison J. T., Portugal P., 2002. Job search methods and outcomes. Oxford Economic Papers 54 (3), 505-533.

[2] Bentolila, S., Michelacci, C., Suarez, J., 2010. Social Contacts and Occupational Choice. Economica $77,20-45$.

[3] Binmore K., Rubinstein A., Wolinsky A., 1986. The Nash Bargaining Solution in Economic Modelling. The RAND Journal of Economics 17 (2), 176-188.

[4] Boxman E.A.W., De Graaf P.M., Flap H.D., 1991. The impact of social and human capital on the income attainment of Dutch managers. Social Networks 13, 51-73. 
[5] Brown M., Setren E., Topa G., 2012. Do informal referrals lead to better matches? Evidence from a firm's employee referral system. Staff Report, Federal Reserve Bank of New York, No. 568.

[6] Bureau of Labor Statistics. www.bls.gov.

[7] Cahuc P., Fontaine F., 2009. On the Efficiency of Job Search with Social Networks. Journal of Public Economic Theory 11 (3), 411-439.

[8] Capellari L. Tatsiramos K., 2013. With a Little Help from My Friends? Quality of Social Networks, Job Finding Rates and Job Match Quality. Working Paper.

[9] Card D., 2001. Estimating the Return to Schooling: Progress on Some Persistent Econometric Problems. Econometrica 69, 1127-1160.

[10] Cingano F., Rosolia A., 2012. People I Know: Job Search and Social Networks. Journal of Labor Economics 30 (2), 291-332.

[11] Corak M., Piraino P., 2011. The Intergenerational Transmission of Employers. Journal of Labor Economics, 29(1), 37-68.

[12] Delattre, E., Sabatier, M., 2007. Social Capital and Wages: An Econometric Evaluation of Social Networking's Effects. Labour 21, 209-236.

[13] Fontaine F., 2008. Why Are Similar Workers Paid Differently? The Role of Social Networks. Journal of Economic Dynamics and Control 32(12), 3960-3977.

[14] Galenianos M., 2012. Hiring through Referrals. SSRN working paper.

[15] Gautier P., 2002. Unemployment and Search Externalities in a Model with Heterogeneous Jobs and Workers. Economica 69, 21-40.

[16] Gautier P. A., Teulings C. N., van Vuuren A., 2010. On-the-Job Search, Mismatch and Efficiency. Review of Economic Studies 77 (1), 245-272.

[17] Glitz A., 2013. Coworker Networks in the Labour Market. CESIfo Working paper No. 4250.

[18] Goos M., Salomons A., 2007. Dangerous liaisons: a social network model for the gender wage gap. Discussion paper series, No. 07.22.

[19] Granovetter M., 1995. Getting a Job: A Study of Contacts and Careers. The University of Chicago Press.

[20] Hagedorn M., Manovskii I., 2008. The Cyclical Behavior of Equilibrium Unemployment and Vacancies Revisited. The American Economic Review 98 (4), 1692-1706.

[21] Hall and Milgrom P., 2008. The Limited Influence of Unemployment on the Wage Bargain. American Economic Review 2008, 98:4, 1653-1674.

[22] Hensvik L., Nordstrom-Skans O.N., 2013. Social Networks, Employee Selection and Labor Market Outcomes. IFAU working paper, No. 2013:15.

[23] Hobijn B., Sahin A., 2009. Job-finding and separation rates in the OECD. Economics Letters 104 (3), 107-111.

[24] Horvath G., 2013. Occupational mismatch and social networks. Working paper, Southwestern University of Finance and Economics.

[25] Ioannides Y.M., Datcher Loury L., 2004. Job Information Networks, Neighborhood Effects, and Inequality. Journal of Economic Literature 42(4), 1056-1093.

[26] Ioannides Y.M., Soetevent A. R., 2006. Wages and Employment in a Random Social Network with Arbitrary Degree Distribution. The American Economic Review 96 (2), 270-274. 
[27] Kramarz F., Nordstrom-Skans O., 2011. When strong ties are strong - networks and youth labor market entry. IFAU working paper, No. 2011-18.

[28] Kugler A. D., 2003. Employee Referrals and Efficiency Wages. Labour Economics 10, 531-556.

[29] Margolis D.N., Simonnet V., 2003. Educational Track, Networks and Labor Market Outcomes. IZA discussion paper No. 699.

[30] Meliciani V., Radicchia D., 2011. The informal recruitment channel and the quality of job-worker matches: an analysis on Italian survey data. Industrial and Corporate Change 20(2), 511-554.

[31] Montgomery J.D., 1991. Social Networks and Labor-Market Outcomes: Toward an Economic Analysis. American Economic Review 81, 1408-1418.

[32] Montgomery J.D., 1992. Job Search and Network Composition: Implications of the Strength-OfWeak-Ties Hypothesis. American Sociological Review 57 (5), 586-596.

[33] Montgomery J.D., 1994. Weak Ties, Employment, and Inequality: An Equilibrium Analysis. American Journal of Sociology 99 (5), 1212-1236.

[34] Mortensen D.T., Vishwanath T., 1994. Personal Contacts and Earnings It is who you know! Labour Economics 1, 187-201.

[35] Mortensen D., 2003. Why are similar workers paid differently? Cambridge: MIT Press.

[36] Neal D., Rosen S., 2000. Theories of the distribution of earnings. Handbook of Income Distribution Volume 1 (Chapter 7), 379-427.

[37] OECD, 2013. Education at a Glance: OECD Indicators. OECD Publishing.

[38] Pelizzari M., 2010. Do Friends and Relatives Really Help in Getting a Good Job? Industrial and Labor Relations Review 63 (3), 494-510.

[39] Pissarides C.A., 2009. The Unemployment Volatility Puzzle: is Wage Stickiness the Answer? Econometrica 77 (5), 1339-1369.

[40] Pistaferri L., 1999. Informal Networks in the Italian Labor Market. Giornale degli Economisti e Annali di Economia 58 (3-4), 355-375.

[41] Ponzo M., Scoppa V., 2010. The use of informal networks in Italy: Efficiency or favoritism? The Journal of Socio-Economics 39 (1), 89-99.

[42] Rivera M.T., Soderstrom S.B., Uzzi B., 2010. Dynamics of Dyads in Social Networks: Assortative, Relational, and Proximity Mechanisms. Annual Review of Sociology 36, 91-115.

[43] Saloner G., 1985. Old Boy Networks as Screening Mechanisms. Journal of Labor Economics 3(3), 255-267.

[44] Shimer R., 2005. The Cyclical Behavior of Equilibrium Unemployment and Vacancies. The American Economic Review 95 (1), 25-49.

[45] Simon C. J., Warner J. T., 1992. Matchmaker, Matchmaker: The Effect of Old Boy Networks on Job Match Quality, Earnings, and Tenure. Journal of Labor Economics 10 (3), 306-330.

[46] Staiger D., 1990. The Effect of Connections on the Wages and Mobility of Young Workers. Dissertation, MIT.

[47] Sylos Labini M., 2004. Social Networks and Wages: It is all about connections! LEM Working Paper Series, No. 2004/10.

[48] Teulings C. N., Gautier P. A., 2004. The Right Man for the Job. Review of Economic Studies 71 (2), 553-580. 
[49] Tumen S., 2013. Informal versus Formal Search: Which Yields a Better Pay? MPRA Paper No. 50446 .

[50] Zaharieva A., 2012. Double Matching: Social Contacts in a Labour Market with On-the-Job Search. IMW Working Paper No. 473. 